Review

\title{
Mechanisms Underlying Cytotoxicity Induced by Engineered Nanomaterials: A Review of In Vitro Studies
}

\author{
Daniele R. Nogueira ${ }^{1}$, Montserrat Mitjans ${ }^{2,3}$, Clarice M.B. Rolim ${ }^{1}$ and M. Pilar Vinardell ${ }^{2,3, *}$ \\ 1 Departamento de Farmácia Industrial, Universidade Federal de Santa Maria, Santa Maria, RS, \\ 97105-900, Brazil; E-Mails: daniele.rubert@gmail.com (D.R.N.); \\ clarice.rolim@gmail.com (C.M.B.R.) \\ 2 Departament de Fisiologia, Facultat de Farmàcia, Universitat de Barcelona, Barcelona 08028, \\ Spain; E-Mail: montsemitjans@ub.edu \\ 3 Unidad Asociada al CSIC, Barcelona 08028, Spain \\ * Author to whom correspondence should be addressed; E-Mail: mpvinardellmh@ub.edu; \\ Tel.: +34-934-024-505; Fax: +34-934-035-901.
}

Received: 8 May 2014; in revised form: 28 May 2014 / Accepted: 3 June 2014 /

Published: 12 June 2014

\begin{abstract}
Engineered nanomaterials are emerging functional materials with technologically interesting properties and a wide range of promising applications, such as drug delivery devices, medical imaging and diagnostics, and various other industrial products. However, concerns have been expressed about the risks of such materials and whether they can cause adverse effects. Studies of the potential hazards of nanomaterials have been widely performed using cell models and a range of in vitro approaches. In the present review, we provide a comprehensive and critical literature overview on current in vitro toxicity test methods that have been applied to determine the mechanisms underlying the cytotoxic effects induced by the nanostructures. The small size, surface charge, hydrophobicity and high adsorption capacity of nanomaterial allow for specific interactions within cell membrane and subcellular organelles, which in turn could lead to cytotoxicity through a range of different mechanisms. Finally, aggregating the given information on the relationships of nanomaterial cytotoxic responses with an understanding of its structure and physicochemical properties may promote the design of biologically safe nanostructures.
\end{abstract}

Keywords: in vitro methods; cytotoxicity; nanomaterials; cell culture; nanosafety 


\section{Introduction}

The most common definition of nanotechnologies includes materials with at least one dimension in the range of 1 to $100 \mathrm{~nm}[1,2]$, although some authors classify them as all submicronic particles up to $200 \mathrm{~nm}[3,4]$, or even up to $1000 \mathrm{~nm}[5,6]$. At this size, nanomaterials (NMs) might interact in a unique fashion with biological systems and be easily taken up by cells [7], which opens up a wide range of interesting applications in medicine [8]. However, the same characteristics that make the NMs a promising approach for many new clinical therapies also make them very reactive structures that can generate undesirable cell interactions and adverse effects.

Similarly, nanotechnologies may change many sectors of industry for the better, though considerable concern has arisen in these different industrial fields about their side effects and possible risks to human life. It is clear that the potential toxicity of nanoparticles (NPs) versus biological systems has to be much more thoroughly investigated than has been done to date in order to define their future role in clinical, diagnostic, technological and environmental applications.

Concerning the unique properties of the NMs, a new research field of toxicology, namely nanotoxicology, was defined to address gaps in knowledge and also to assess the problems likely to be caused by nano-sized materials [9]. More specifically, nanotoxicology aims to understand the principles and mechanisms of interactions at the nano-bio interface and also to determine the relationship between NM physicochemical properties and the associate toxicological profiles [10]. It is a fact, with open discussions in the scientific community, that NM composition, size, geometry, and transport or durability in the body, can cause adverse effects on human health. Furthermore, due to their specific intrinsic properties, the NMs have a big tendency to suffer cellular uptake, which may also result in bioaccumulation and, thus, in increasing the adverse effects and toxic potential [11]. Moreover, it is widely described that NMs presented great chemical reactivity, which may lead to many kinds of toxic reactions, including mutagenicity by formation of DNA adducts or sensitization by hapten binding [1].

For most engineered NMs, toxicity data are unavailable or the data reported show very controversial and inconclusive results [1]. In such a context, an understanding of the toxicity mechanisms is crucial for both the design of more efficient NMs, and at the same time for the design of nanotechnologies that are biologically and/or environmentally benign throughout their life-cycle.

Although numerous in vitro nanotoxicity studies have already been published, most of the experiments carried out thus far have used particles not well characterized regarding their composition and physicochemical properties. However, such a characterization is mandatory since nanoparticles might interact with assay components or interfere with detection systems resulting in unreliable data. Aspects related to the importance of a detailed characterization of the NMs prior to any in vitro studies are also reviewed and commented in this article in Section 3.

A wide range of in vitro approaches has been used to assess the toxicological behavior of different types of NMs. However, many traditional approaches might have even greater limitations for NP than for other conventional chemicals and also may not offer the throughput and velocity to handle the dynamic developments in nanotechnologies [1]. Therefore, it is worth mentioning that novel approaches need to be developed in order to cover the needs of nanotoxicology. 
The issue of safety and risk assessment of NMs becomes complicated because they are not a uniform group of substances $[12,13]$. Therefore, a huge problem concerning the toxicological aspects of NMs is the wide range of nanotechnologies with different chemical compositions, overall physicochemical characteristics and sizes. Along these lines, emerging information on quantitative structure-activity relationship (QSAR) modeling of NMs' toxic effects is gaining force toward the construction of a database platform including the toxicological information of different NMs, interrelated with the physicochemical characteristics and chemical composition of each NM. The application of a structure-activity paradigm to NMs represents a promising approach to anticipate their toxicological properties in a fast and inexpensive way. Likewise, following this paradigm, it is possible to predict the toxic effects induced by NMs on the basis of some structural similarities with chemicals for which toxicological behavior have been previously determined [14].

Up until now, no NM-specific risk assessment paradigms have been produced, and therefore, researchers took liberal approaches to studying its toxicity [8,15]. For example, within the European Union, REACH (Registration, Evaluation, Authorisation and Restriction of Chemical substances) is for the time being the basis of NM risk assessment, even though no specific legislation is assigned specifically to NM analysis [16]. The regulatory agencies continuously reported that efforts to address the human toxicity of NMs should be directed towards developing models that predict associations between changes to NM physicochemical characteristics and hazardous properties [17]. Following this line, high throughput in vitro cellular models have been receiving growing attention toward establishment of rapid and reliable approaches for nanotoxicology assessments.

Considering the special properties of NMs that can lead to toxic effects, many strategies have been applied to improve performance and reduce toxicity of NMs in medical design, i.e., the use of coating materials and/or the development of biocompatible/biodegradable NPs [18]. Independently of the approach used to design a new drug delivery system, its toxicological properties must be assessed by using, for example, in vitro cellular models for a primary screening and also for the elucidation of some inherent mechanism underlying toxicity of each type of nanodevice. There is growing concern regarding the interrelationship between particle size, shape, chemical composition and toxicological effects of NMs, which are demonstrated by the increasing number of studies considering this subject $[19,20]$.

As already highlighted, the number of research articles concerning nanotoxicology has been growing significantly in the last decade. However, most of the data published is related to toxicological phenomena and the comprehension of the underlying mechanisms for NM-induced toxicity are less explored and understood. Therefore, the increasing usage of engineered NMs, especially in health concerns, has emphasized the need for further mechanistic insight to predict the consequences of exposure to this new class of materials.

The characterization of the risks of the NMs is highly complex because of the special and specific physicochemical properties of such materials. In searching for a testing strategy that can rapidly and efficiently provide a screening approach for evaluating the potential hazard of NMs, researchers have been using a wide range of in vitro cellular models in an attempt to determine the toxicological behavior of NMs and to elucidate the mechanisms underlying this toxicity. 


\section{In Vitro Toxicity Assessment}

The wide variety of in vitro and in vivo assays that are employed to assess NP toxicity has been used because these are the tools that were already available for molecular toxicology when nanoparticle toxicity questions first arose. The first major problem with using these assays is that the modes of NP toxicity might not be the same as those incurred by molecular toxicants. Because of the expense of animal testing in toxicology and pressure from both the general public and government to develop alternatives to in vivo testing, in vitro cell-based approaches might be more attractive and necessary for NM toxicity assessment [21]. In vitro testing is a common first step in assessing the health risks related with engineered NMs. Despite the frequent lack of consistency or predictability between in vitro models and in vivo observations, there is little rational or ethical justification to proceed directly from material synthesis to animal models [22]. Moreover, some effects can be seen only in vitro and thus hazards that are masked by current in vivo tests due to animal defenses should not be underestimated [1]. Therefore, it is desirable to develop and validate simple non-in vivo assays for the purpose of predicting in vivo responses in order to reduce and avoid extensive testing using laboratory animals [23].

The primary focus of the in vitro assays is to assess the cytotoxic effects of chemicals and, more recently, of nano-based forms of such chemicals. However, the in vitro assays have many features and advantages to be used in more specific studies, i.e., to study the mechanisms underlying cytotoxicity induced by chemicals or NMs. In vitro approaches allowed researchers to obtain faster and more reliable mechanistic information on nanotoxicology. It is worth mentioning that the application of the in vitro methods to NMs do not follow a validated process. Hartung [1] described a number of alternative methods validated for chemicals and drugs that might be useful for NMs. Moreover, the author stated that efforts directed at the validation of the existing methods for NPs would not only expand the applicability domains of these validated methods, but might also allow a possible fast-track to obtaining regulatory acceptance for NP evaluation.

On the other hand, there are some concerns about the growing use of in vitro methods for nanotoxicity assessments. Discussions are constantly raised about the fact that such alternative methods are less applicable to particles than to soluble chemical substances, mainly due to their particularly physicochemical properties. Indeed, some of these concerns apply to NM structure and characteristics, e.g., the in vitro kinetics of particles (their behavior in cell culture) might differ, including in terms of phenomena such as particle aggregation, binding to plastic and/or floating on the cell culture media surface [15,24]. Similarly, air exposure and specific artifacts used in cytotoxicity assays (i.e., MTT or NR dyes) might interfere in the in vitro experiments $[1,25,26]$. In this case, intrinsic photometric absorbance or fluorescence of NMs may alter colorimetric or fluorometric assay reporting. Moreover, the high surface energy and surface area of NMs may also contribute to the binding of unanticipated amounts of assay reagent or analyte [22]. However, the nanotoxicology is a new subject that is likely a driving force and not a declining influence regarding the use of modern approaches in toxicology $[1,27,28]$. In vitro methods have many advantages over the in vivo experiments, especially concerning the comprehension of the mechanisms underlying the toxic effects of NMs. 
There are some authors that believe the first approach to proceed with a toxicological assessment of $\mathrm{NMs}$ is to use acellular systems to explore the reactivity of the materials in such acellular environments $[23,29,30]$. NMs that do not produce reactive species are seen as having a lower capacity for inducing significant toxic responses in biological systems. After this initial characterization, it would be possible to proceed to in vitro cellular models by using testing methods with relevant endpoints such as cytotoxicity, apoptosis, cell-cycle alterations, skin and ocular toxicity, genotoxicity, potential carcinogenicity and effects on the immunological system [13]. The underlying mechanisms of toxicity for NMs are remarkably complicated, hence the need for dedicated and specific analytical methodology and tools.

Interestingly, many of the research articles that consider the mechanisms underlying cytotoxicity, using specifically in vitro assays, have focused on more than one mechanism of cell interaction [20,31]. This is important in order to obtain some correlation between each cell disturbance effect and also to determine a sequence of mechanisms and specific NM-cell interactions that would ultimately to toxic effect.

Despite the great importance and validity of the in vitro model to screen compounds and identify the type of effect induced on cells, it is necessary to recognize that they may not be sufficient for defining safe exposure limits [32]. Simple in vitro methods are totally relevant for initial toxicity screening studies of NMs, as well as determining some mechanisms underlying cell interaction that may be responsible for their cytotoxicity. However, more physiologically relevant in vitro models or even in vivo assays might be useful and necessary to better understand how NMs can impact human health at all.

\subsection{Cytotoxicity Activity}

\subsubsection{Cytotoxicity Assays}

The cytotoxicity data of most of the tested NMs have been generated by using tetrazolium salt-based endpoints. The 3-(4,5-dimethylthiazol-2-yl)-2,5-diphenyl-tetrazolium bromide (MTT), 3-(4,5-dimethylthiazol-2-yl)-5-(3-carboxylmethoxyphenyl)-2-(4-sulfonyl)-2H-tetrazolium) (MTS), 2,3-bis-(2-methoxy-4-nitro-5-sulfophenyl)-2H-tetrazolium-5-carboxanilide) (XTT), and the water-soluble tetrazolium salts (WST-8 and WST-1) assays are widely reported in the literature with this purpose.

The MTT approach is the most common assay, and has been extensively applied to assess the effect of a variety of NMs on cell viability [7,31,33-38]. This method measures the reduction of MTT salt to a colored insoluble formazan in active mitochondria in viable cells [39]. Moreover, this assay can be applied either for cytotoxicity and cell proliferation studies.

The cytotoxicity endpoint MTS was applied for monitoring the cytotoxic responses of gold NPs [40] and of cationic polystyrene nanosphere [41]. Moreover, MTS was also applied to determine the cell damage induced by bioadhesivepoly(anhydride) NPs destined for oral antigen/drug delivery. HepG2 and Caco-2 were used as model cell lines, the last one also being used in studies to discriminate between cytoadhesion and cytoinvasion mechanisms of cell interaction [42].

Although to a lesser extent, the XTT assay has also been applied, e.g., to assess the cytotoxicity of citrate stabilized gold NPs in three cell lines [43] and of bio-active silica NPs in 19 different cell lines 
representing all major organ types [44]. Specifically, in the later study, the results revealed little toxicity in any cell type analyzed and, therefore, the cell line characteristics did not influence the final toxic response. However, many authors have demonstrated that the organ and species of cell used in the cytotoxicity study have strong effects on the outcoming results [31,33,45]. The single characteristics of each cell line can make it less or more sensitive to the cytotoxic effects of a NM. As a general rule, the selection of a relevant cell type depends on the expected in vivo target organ and application of the NPs.

The WST assays have appeared to be advantageous over MTT in that they are reduced outside cells, and yield a yellow-colored water-soluble formazan, which is soluble in the tissue culture medium. WST-8 assay was conducted to determine the cytotoxic potential of two-dimensional carbon-based NMs, including graphene sheets (GS) and graphene oxide (GO) [38], as well as to measure metabolic activity of six cell lines from different organs and species after exposure to silica NPs [45], and carbon black (CB), single-wall carbon nanotube, silicon dioxide $\left(\mathrm{SiO}_{2}\right)$ and zinc dioxide ( $\left.\mathrm{ZnO}\right)$ NPs [19]. In another study, WST-8 endpoint was used to evaluate the cell proliferation of hepatic stellate cells (HSCs) treated with silver NPs [46]. Likewise, WST-1 derived assay is also a colorimetric technique that allows the quantitative determination of cell viability. It was used by Ghosh et al. [37] to determine the cytotoxicity of $\mathrm{TiO}_{2}$.

The neutral red uptake assay (NRU) is also a simple endpoint commonly used to evaluate the cytotoxicity of different NMs [7,20,36,37]. It measures the uptake of the NR dye by viable cells with intact plasma membrane, and its concentration in lysosomes.

Trypan blue staining is a dye exclusion assay, used to measure cell membrane integrity, and has been applied to determine the effects of gold [47] and $\mathrm{TiO}_{2}$ [37] NPs on cell membrane damage. Likewise, Nymark et al. [48] applied this simple cytotoxicity assay to determine the cytotoxicity of polyvinylpyrrolidone (PVP)-coated silver NPs by counting the number of living (unstained) cells using a phase-contrast microscopy. Moreover, Karlsson et al. [49] determined the potential of cooper-containing NPs to alter the cell membrane integrity by using this approach. Alternatively, these authors used the hemolytic assay and hemoglobin interactions to assess the particle-cell membrane interactions and, thus its cytotoxicity. Finally, Chueh et al. [40] counted trypan blue-stained cells (dead) on a hemocytometer under a microscope for the determination of cell growth curve after gold NPs treatment.

Alternatively, cell membrane integrity can be assessed by monitoring the passage of substances that are normally sequestered inside cells to the outside, i.e., lactate dehydrogenase (LDH), which is commonly measured by the LDH leakage assay. This assay has been used in many kinds of studies on NM toxicity. Sun et al. [46] performed this assay to assess the acute toxicity of silver NPs on HSCs cells. Likewise, LDH release was measured to determine the cytotoxicity of cationic surfactant-based nanoparticles and micelles on neutrophils [50], and of multi-walled carbon nanotubes (MWCNTs) in four different cell lines [51].

Luminescent cell viability assay is another cytotoxicity assay employed in nanotoxicological studies, e.g., on PVP-coated silver NPs [48] and citrate stabilized gold NPs [43]. This assay determines the number of viable cells based on the quantification of ATP, which signals the presence of metabolically active cells. Darolles et al. [52] also performed intracellular ATP measurements to determine the cytotoxicity of cobalt oxide particles against cell metabolism. The authors used a commercial kit that measures the luminescence luciferase conversion to oxyluciferin. 
Additionally, the resazurin (Alamar Blue) reduction assay, with fluorometric measurement, has

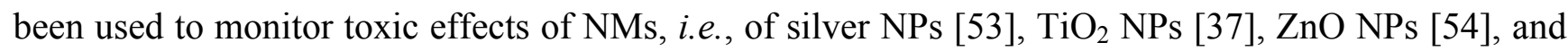
of multi-walled carbon nanotubes (MWCNTs) [51]. The number of viable cells correlates with the magnitude of dye reduction and, thus, also gives an overview of the cell's metabolic condition.

CBQCA total protein cell viability test is a specific assay that assesses the survival/viability and is based on the capacity of the cells to incorporate and bind a fluorescent dye (ATTO-TAG CBQCA) to the protein amines. Robbens et al. [8] used this approach to assess the effects of bio-active NPs and polyplexes on hepatocytes cell growth. A toxic chemical will result in a reduction of the growth rate as reflected by cell number, and this response is highlighted by the decrease of fluorescence of the amine bound CBQCA.

Clonogenic assay were applied to count the colony numbers for determine cytotoxicity of gold NPs in two different studies [40,47]. Moreover, Darolles et al. [52] applied this assay to assess the cytotoxicity of cobalt oxide particles. In this assay, a colony is defined as at least 50 clones of one initial cell, and its count is performed through staining with crystal violet $(0.5 \%)$. Besides, the cell growth assay, performed by using a Z1 counter, was applied to determine the effect of gold NPs on cytokinesis of three different cell lines [33]. Moreover, these authors used the colony-forming assays to determine the long-term cytotoxic of the same NPs.

Another popular method is to stain the entire cell or specific cellular components with fluorescent dyes. This approach allows rapid detection via flow cytometry, and can be combined with microscopy-based analysis to evaluate, i.e., morphological features like cell spreading. In this line, viability measurements after zinc oxide NPs exposure have been performed using a mix of fluorescein diacetate (FDA) and ethidium bromide (EtBr) fluorescent dyes [55]. Cells were stained with a 1:1 solution of $80 \mu \mathrm{g} / \mathrm{mL}$ FDA plus $50 \mu \mathrm{g} / \mathrm{mL}$ EtBr and observed under a fluorescence microscope. In this double-staining method, living cells were stained in green, while dead cells exhibit their nucleus stained in orange. Furthermore, membrane integrity of human lung epithelial A549 cell line treated with engineered cadmium-coated silica NPs was assessed using calcein-AM/propidium iodide (PI) double-staining assay [56]. The cytotoxicity result was given after cell count using fluorescence microscopy. Likewise, quantification of cell viability was performed using PI and fluorescein diacetate (FdA) double staining after HeLa cells treatment with iron oxide magnetic NPs [57]. PI is normally excluded from the inside of healthy cells, but freely cross the membrane and stain intracellular components of cells with compromised membrane. The cells were analyzed by fluorescence microscopy and the cytotoxicity was established by the ratio between viable (green) and dead cells (red) counted on several microscopic fields. Some authors are also using commercial kits to determine the rate of cell proliferation after treatment with NPs. A cell proliferation assay based on the detection of fluorescence/red fluorescent dye that stains nucleic acids was used to determine the cytotoxicity of cobalt oxide particles [52].

A different approach based on a cell-culturing platform (Cell-IQ) has been used as a real-time cell-monitoring system to measure cell biological behaviors, including the total cell number, number of dead cells and cell movement. Sun et al. [46] applied this technology to study the behavior of HSCs cells after treatment with silver NPs. In this same line, an electrical measurement known as Electric Cell-Substrate Impedance Sensing (ECIS) was applied to real-time monitoring of in vitro cellular cytotoxicity of silica nanotubes [58] and gold NPs [47]. This technique has been used to study cellular viability and proliferation, and also has the advantages to be label-free and non-invasive in comparison 
with other conventional viability assays. Likewise, real-time cell analysis (RTCA) system was used for continuous monitoring of changes in cell growth after treatment with gold NPs [40]. This system is also based on the measurement of cell impedance for continuous monitoring of cell growth.

Recently, a new approach, called single-cell mechanics, which is derived from atomic force microscopy-based single-cell compression, has been proposed to investigate NM-induced cytotoxicity [59]. The authors proved the validity of this approach by reading force-deformation profiles following known NP treatments utilized previously. Moreover, it was highlighted that this single-cell-based approach is advantageous in terms of being able to directly correlate to in vivo investigations.

Noteworthy is that the utilization of a simple in vitro endpoint can also give some valid information concerning the mechanisms underlying NM-induced cytotoxicity. For example, the widely used MTT assay measures the cell metabolic activity in the mitochondria of viable cells and can thus be used as a parameter to determine both cell metabolism and any damage to the mitochondrial compartments [20]. Moreover, the NRU assay reflects the functionality of the lysosomal membrane [60]. Finally, the LDH assay measures severe cell damage and is an indicator of plasma membrane integrity [19]. Therefore, due to their specific mechanisms, these different endpoints can display varied sensitivity to detect the cytotoxic effects of chemicals. The utilization of complementary assays in the same study, each one based on a different mechanism for toxicity detection, is therefore strongly recommended [61,62].

Finally, it is known that NMs interfere with several assay systems, leading some researchers to dedicate efforts to understanding the specific behavior of different NMs with cell viability endpoints. Monteiro-Riviere et al. [26] reported that aluminum NPs interact with the MTT assay, and to a lesser extent, with CellTiter $96^{\circledR}$ AQueous One (96 AQ; Promega Corp, Madison, WI, USA) and Alamar blue $^{\circledR}$ (aB; Invitrogen, Carlsbad, CA, USA) viability assays. Likewise, it was demonstrated that carbon-based NPs interacted with some widely used viability assays, including Alamar blue, NRU and MTT [25]. These interactions led to an apparent increase in viability and thus to a misinterpretation of the cytotoxicity data, which highlighted the importance of the combination of more than one assay when determining NP toxicity for risk assessment. Recently, Guadagnini et al. [63] published a specific study on the interferences of NMs with assay processes and components of classic in vitro tests. The authors have provided a great overview of the main challenges of the conventional viability assays when applied to nanostructures.

\subsubsection{Three-Dimensional (3D) Cell Culture Systems}

Clinically relevant in vitro models, such as the 3D cell culture systems, have been manufactured to mimic the properties of tissue in vivo. Hashimoto et al. [64] developed a novel 3D system using murine macrophages (RAW 264.7 cell line) to assess the biological effects of polyvinylpyrrolidone-coated silver NPs. The authors observed that the cytotoxic results differ between 2D and 3D cultures, the 3D culture system being less sensitive to the NP cytotoxic effects.

In another study, a 3D in vitro model was proposed to evaluate the potential of carbon nanotubes to form epithelioid granulomas in nonadherent primary murine bone marrow-derived macrophages (BMDM), cultures in a 3D system [65]. The results of this study showed the distinctive morphological and phenotypic responses of the 3D culture, which suggest this in vitro model as a potential alternative to both traditional 2D monolayer cultures and to rodent bioassays for granuloma formation (Figure 1). 
Figure 1. Light microscopic morphology and kinetics of macrophage aggregation in $2 \mathrm{D}$ and 3D cultures. BMDM were exposed to $0.5 \mu \mathrm{g} / \mathrm{mL}\left(0.38 \mu \mathrm{g} / \mathrm{cm}^{2}\right)$ of particulates. Formation of stable cellular aggregates was evaluated at 3 and 14 days post-exposure. Macrophages were stained with May-Grünwald-Giemsa. Reprinted from [65]. Open Access article, under the terms of Creative Commons Attribution License. Copyright 2011, Licensee Biomed Central Ltd.

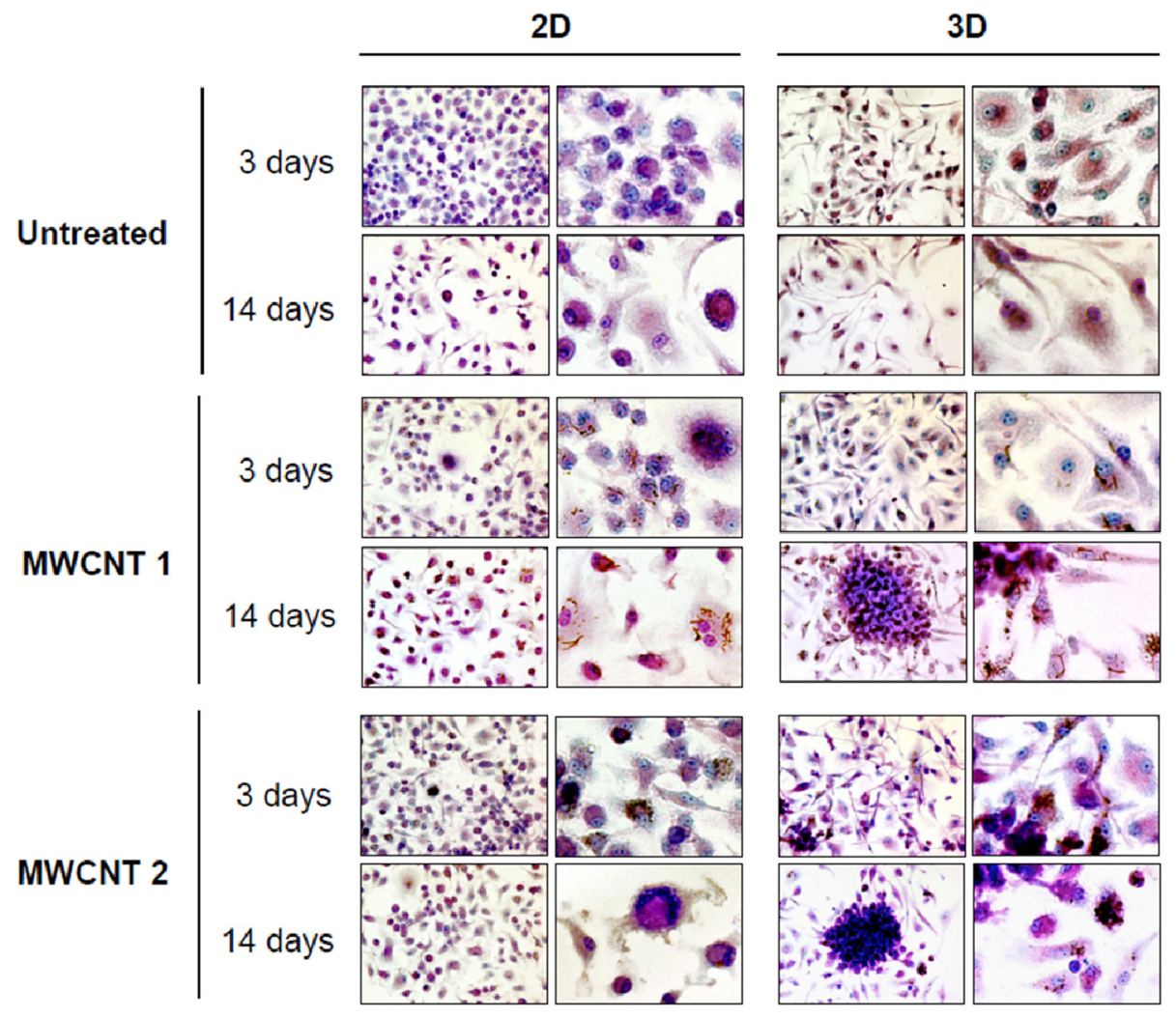

The 3D cell culture systems have also been applied as a useful tumor model to study the antitumor activity of a wide range of NMs. 3D-tissue-engineered tumor models have the potential to bridge the gap between monolayer cultures and patient-derived xenografts and, in this context, were applied to test different NP-based chemotherapeutics [66-68]. Xu et al. [69] developed a hydrogel-derived prostate cancer model, in which the cancer cells were entrapped in hyaluronic acid matrices to form distinct tumor-like multicellular aggregates. Finally, the application of $3 \mathrm{D}$ in vitro models to study the advantages of nanotechnology for cancer therapy has been recently reviewed [70].

\subsection{Alterations of Enzymatic Activity}

Acetylcholinesterase $(\mathrm{AChE})$ and butyrylcholinesterase $(\mathrm{BChE})$ are important enzymes in the area of neurobiology, toxicology and pharmacology. Inhibition of AChE causes the accumulation of acetylcholine, interfering with the function of the nervous system. On the other hand, inhibition of BChE could result in the accumulation of acetylcholine in neural synapses, which can disrupt the nervous system normal function. In a recent study, it was demonstrated that silver NPs inhibited both the activity of $\mathrm{AChE}$ and $\mathrm{BChE}$ in vitro, by using an enzyme assay with o-nitrophenyl acetate or o-nitrophenyl butyrate as substrates, respectively [71]. The extent of ChEs inhibition was shown to be 
dependent on the surface coating of silver NPs, and these preliminary findings suggest that metallic NPs had an inhibitory potential on the metabolism of xenobiotics governed by the cholinesterases. Finally, the authors stated that the tested enzyme assays offer practical implementation in the toxicokinetic studies of metallic NPs.

The adsorption and inhibition of AChE [72] and BChe [73] by different NMs, including three metal NPs $(\mathrm{Cu}-\mathrm{C}, \mathrm{Cu}$ and $\mathrm{Al})$, three oxides $\mathrm{NPs}\left(\mathrm{SiO}_{2}, \mathrm{TiO}_{2}\right.$ and $\left.\mathrm{Al}_{2} \mathrm{O}_{3}\right)$ and two carbon nanotubes (MWCNT and SWCNT) have been assessed. In these experiments, the Ellman assay [74] was used to measure the activity of both enzymes and calculate the inhibition rate, because NPs could adsorb the yellowish product, 50-mercapto-20-nitrobenzoic acid (5-MNBA) during the color development, which does not allow a simple colorimetric enzyme activity assay. The samples were finally read at $410 \mathrm{~nm}$ by spectrophotometry.

The effects of different classes of NPs on the enzymatic activity of the cytosolic protein human arylamine N-acetyltransferase 1 (NAT1) was recently investigated [75]. The importance of NAT1 lies in the fact that it is a drug-metabolizing enzyme responsible for the activation and detoxification of known carcinogens. NMs including metal oxides, synthetic clay NPs and a self-assembling thermo-responsive polymeric NP that differ in size and surface characteristics were used to perform the study. The results suggested that enzyme activity may be compromised in organs exposed to NPs and, thereby highlighting the importance of the evaluation of NP-enzyme interactions.

The binding of luciferase with citrated-coated silver NPs was studied by Kakinen et al. [76]. It was demonstrated that luciferase readily bound to NPs through electrostatic interactions and, thus, the authors analyzed whether the enzyme activity was hindered as a result of the interaction by using different analytical techniques such as UV-vis spectrophotometry, transmission electron microscopy, circular dichroism (CD) spectroscopy and inductively coupled plasma mass spectrometry. The combination of these mechanistic studies may give the basis for facilitating the understanding of NM implications at the molecular level.

Polyamidoamine dendrimers with different surface charges (positive, negative and neutral) were studied in respect to their ability to interact with porcine pepsin, a negatively charged protein [77]. The enzymatic activity of pepsin was measured by UV spectrophotometry, followed by CD spectroscopy analysis. The dendrimers with positive and neutral surface charges were able to inhibit enzymatic activity, whereas the negatively charged dendrimer had no influence on the activity of pepsin, probably due to the electrostatic repulsion.

On the other hand, novel polymeric NPs with mucoadhesion and enzymatic inhibition activity were developed for transnasal insulin delivery [78]. The inhibitory activity of these NPs toward $\alpha$-chymotrypsin, elastase, trypsin and leucine aminopeptidase was tested. The NPs were incubated with substrate solutions and the progress of reaction was followed by monitoring the appearance of the absorption band of $p$-nitroaniline at $410 \mathrm{~nm}$ by UV-Vis spectrophotometry. The tested NPs showed strong inhibitory activity especially toward leucine aminopeptidase present on the nasal mucosa, which demonstrated their potential application as novel drug delivery systems for transnasal delivery of protein and peptide drugs. 


\subsection{Alterations on the Normal Cell Cycle}

Assessment of alterations in the cell cycle has been commonly performed using a fluorescent solution of propidium iodide (PI) and flow cytometry analysis. Apart from the utilization of a PI solution, the cells were incubated with the enzyme RNaseA before flow cytometry analysis. Chuang et al. [47] and Paul et al. [34] evaluated the effects of gold NPs and PLGA NPs on normal cell cycle, respectively, by using this approach. Moreover, Darolles et al. [52] assessed the effects of cobalt oxide particles on the normal cell cycle of BEAS-2B human bronchial epithelial cell line.

Staining the DNA with PI, followed by flow cytometry analysis, was also used to perform the cell cycle analysis of A549 cells after treatment with silver NPs [79]. Ten thousand cells were analyzed, and the percentage of the cells in the sub-G1 phase of the cell cycle was calculated from the total 10,000 cells $(100 \%)$ in the assay, while the percentages for cells in the G0/G1, S and G2/M phases were calculated from the total cells excluding the sub-G1 cells.

\subsection{Induction of Apoptosis and Necrosis}

The fluorescein isothiocyanate (FITC)-annexin V and PI-annexin V double-staining methods have been widely used to detected apoptosis induced by a variety of NMs. These approaches are based on the determination of phosphotidylserine externalization during apoptosis and leakage from necrotic cells. The ratio of apoptotic and necrotic cells after exposure to silica NPs was measured with the annexin V/PI assay by Foldbjerg et al. [45]. This approach analyzed the cells at different stages, i.e., early apoptosis (annexin $\mathrm{V}+^{+} \mathrm{PI}-$ ), late apoptosis/necrosis (annexin $\mathrm{V}+, \mathrm{PI}+$ ) and live (annexin $\mathrm{V}^{-}, \mathrm{PI}^{-}$) cells. Alternatively, apoptotic cell death prompted by gold NPs [40,47], photocopiers emitting NP [80] and food-relevant inorganic NPs [81] were determined using annexin V-FITC binding assays.

McCracken et al. [81] also performed a specific assay to evaluate necrotic cell death (cellular membrane damage) in NP-treated cells. The authors performed a flow cytometric analysis using Sytox Red dead cell stain. As a positive control for cell death, some cells were treated with 10 or $20 \mathrm{mM}$ hydrogen peroxide.

Another double-staining method for apoptosis study is based on the use of the fluorescent dyes acridine orange (AO) and ethidium bromide (EB). By this approach, the treated cells were analyzed by fluorescence microscopy. Nogueira et al. [7,20] used this assay to assess the apoptotic and necrotic potential of $\mathrm{pH}$-sensitive polymeric NPs and nanovesicles, respectively, in both tumor and non-tumor cell lines. Moreover, A549 cells were double stained with AO/EB after treatment with plant latex-capped silver NPs, and their apoptotic potential examined under a fluorescence microscope [82].

Western blot analysis was used to determine if exposure to gold NPs induced expression of various proapoptotic-related proteins [33]. By this assay, procaspase-9, one of thelate apoptosis-initiating proteins of the intrinsic pathway, was analyzed, along with the effector poly (ADP-ribose) polymerase (PARP), a DNA repair enzyme commonly cleaved as a result of caspase-3 and caspase-7 activation. Alternatively, immunofluorescence detection of activated caspase-3 was performed in order to detect the apoptotic pathway of A549 cells after incubation with engineered cadmium-coated silica NPs [56]. The cell samples were incubated with specific antibodies and were counterstained for DNA with PI, and finally examined under a fluorescence microscope. 
Propidium iodide, a fluorescent DNA intercalating agent, has been used to stain and quantify the proportion of cells in the sub-G1 phase of the cell cycle, which is indicative of apoptotic cells. This assay was used by Coulter et al. [33] in order to determine the apoptotic potential of gold NPs and thus to confirm the expression of various proapoptotic proteins previously detected by Western blot analysis.

Paul et al. [34] used various approaches to determine the apoptotic potential of biodegradable poly(lactide-co-glycolide) (PLGA) NPs. Different methods based on cellular morphology analysis under phase contrast microscopy, nucleosomal fragmentation study with DAPI staining and analysis under fluorescence microscopy, and more specifically on AO/EB and annexin V-FITC/PI double staining, were considered for a detailed characterization of apoptosis (Figure 2). Moreover, change in expression of some key apoptotic genes in both mRNA and protein levels, i.e., p53, Bax, Apaf-1, cytochrome c, caspase-9, caspase-3 and Bcl-2, was determine by immunoblot analysis.

Figure 2. (A) Morphological changes of nano-chelidonines (NCs) (10 and $20 \mu \mathrm{g} / \mathrm{mL})$-treated HepG2 cells observed by phase contrast microscope; (B) nuclear condensation assessment of control and treated cells by DAPI staining were analyzed through fluorescence microscopy; (C) the increased apoptotic cells were determined by $\mathrm{AO} / \mathrm{EB}$ staining through fluorescence microscopy. The nuclear condensation and transformation of color green to reddish orange with fragmented nuclear membrane represents the induction of apoptosis in the treated cells with respect to control ones; (D) assessment of cellular apoptosis by externalizing phosphatidyl serine through Annexin V/PI assay by flow-cytometric analysis. Reprinted with permission from [34]. Copyright 2013, Elsevier.

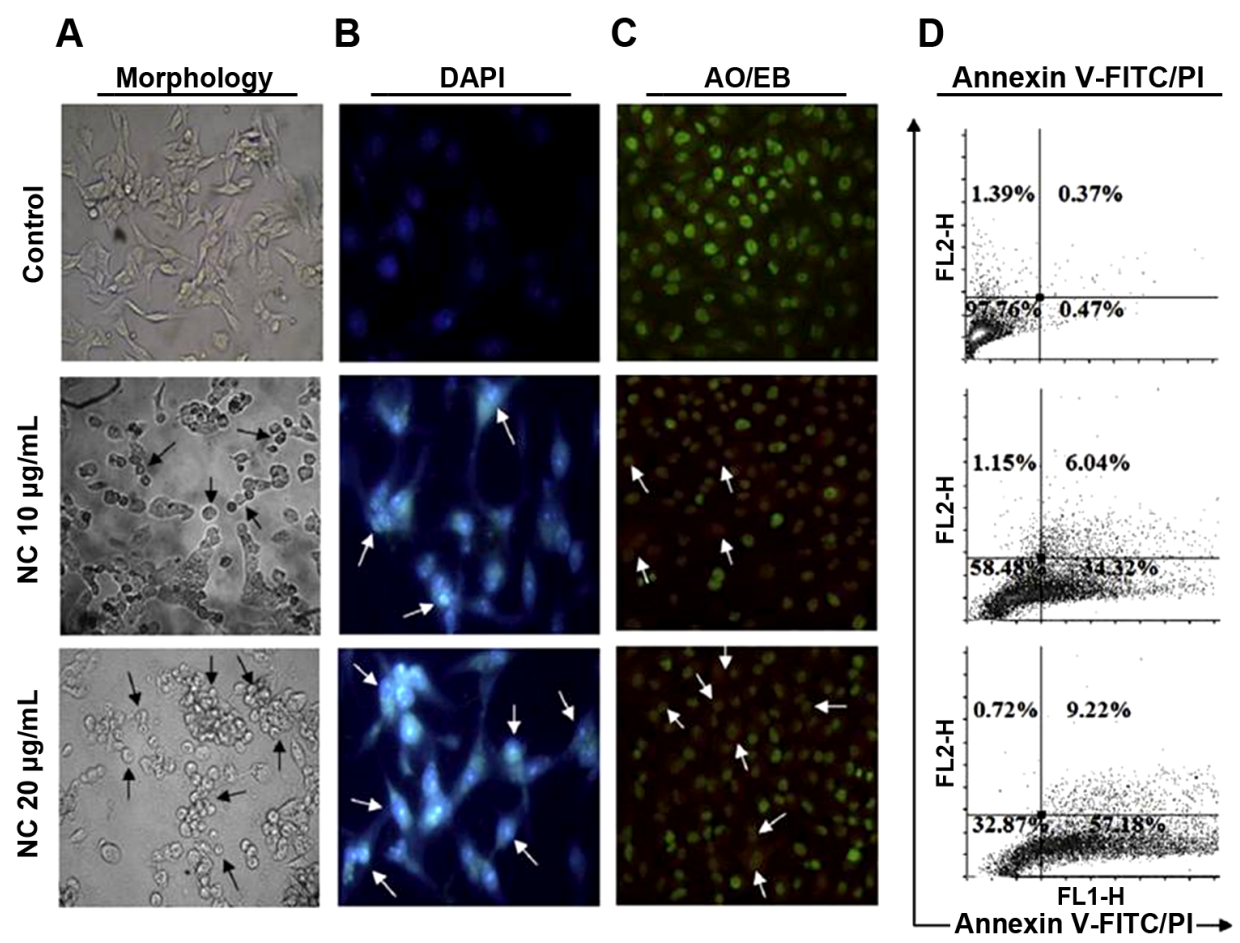

Finally, a cell death detection enzyme-linked immunosorbent assay (ELISA) kit was used to differentiate late apoptosis from necrosis after incubation of J774A.1 mouse macrophages with chromium oxide NPs [83]. The specific enrichment of mono- and oligo-nucleosomes in cell lysates 
(reflecting the level of late apoptosis), and in culture supernatants (reflecting the level of necrosis), was presented as an enrichment factor for each experimental condition.

\subsection{Induction of Oxidative Stress}

Nanomaterial-induced reactive oxygen species (ROS) play a key role in cellular and tissue toxicity. The intracellular ROS production by NM can follow two different pathways: direct ROS generation through NM-catalyzed free-radical reactions in cells, or indirect ROS generation through disturbing the inherent biochemical equilibrium in cells [84]. Because of these different mechanisms, some cell-based assays seek to quantify the ROS species production by cells directly, while others seek to quantify its effects on cell behavior or further production of other cell biochemical reactions.

The intracellular generation of ROS after NM exposure was commonly measured by using the fluorescent marker 2,7-dichlorodihydrofluorescin diacetate (DCFH-DA). DCFH-DA passively enters the cell where it reacts with ROS to form the highly fluorescent compound dichlorofluorescein (DCF). This DCF assay was used to assess the generation of ROS after treatment with different kinds of bovine serum albumin (BSA)-stabilized silica NPs [45] (Figure 3) and of multi-walled carbon nanotubes (MWCNTs) [51], being the cells analyzed by flow cytometry. On the other hand, cell fluorescence was analyzed by fluorimetry to detect ROS production after treatment with silver NPs [53] and CB, single-wall carbon nanotube, $\mathrm{SiO}_{2}$ and $\mathrm{ZnO}$ NPs [19]. Likewise, the derivative fluorescent probe 5-6-chloromethyl- 2'7'-dichlorodihydrofluorescein diacetate acetyl ester was applied to measure ROS level after cell incubation with gold NPs [33].

Figure 3. Measurement of ROS production in A549 cells after $24 \mathrm{~h} \mathrm{NP}$ exposure. The DCF fluorescence of treated cells was normalized to that of untreated controls and reported as mean \pm SD. Reprinted with permission from [45]. Copyright 2013, Elsevier.

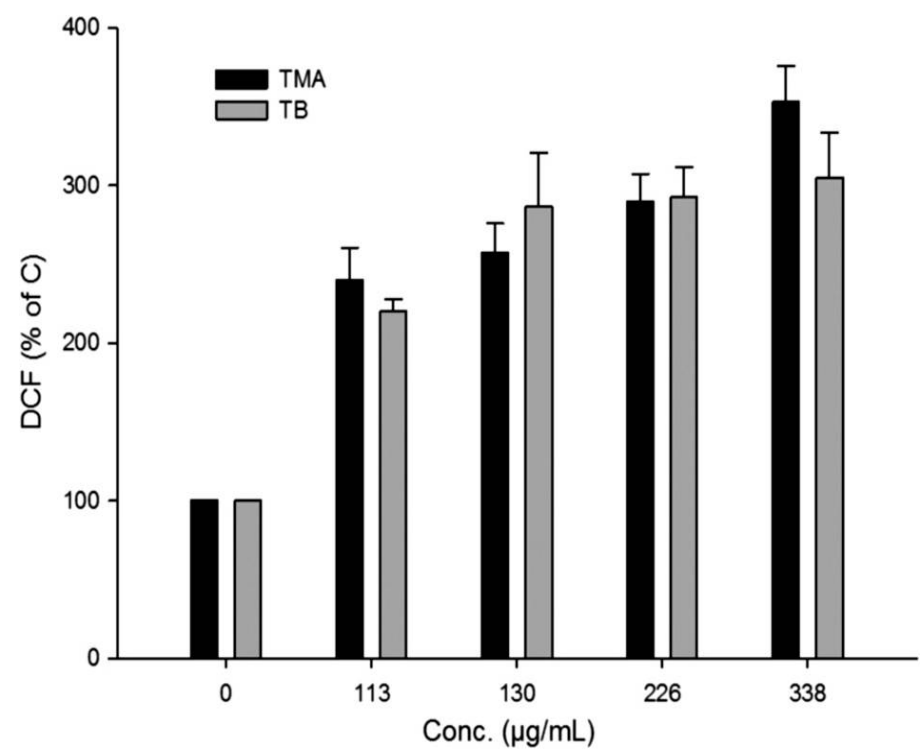

Alternatively, ROS production after cell exposure to NMs has been assessed with the fluorescent probe dihydroethidium (DHE). DHE assay is able to detect superoxide radicals. In cells, DHE reacts with superoxide anion to form ethidium, which exhibits red fluorescence. This assay was applied to determine the dependence of oxidative stress on the size of silica NPs [85] and to assess whether local 
ROS contribute to impair endothelium-dependent vasodilatation in coronary arterioles after NP inhalation [86].

As a more specific assay to detect intracellular peroxide formation, Shen et al. [87] used the MitoSOX Red-based assay to evaluate the mitochondrial superoxide levels as a measure of oxidative stress and intracellular ROS generation. Mitochondria are a major intracellular source of ROS and, thus this assay appears to be more specific and sensitive.

Yang et al. [19] also used the intracellular glutathione (GSH), superoxide dismutase (SOD) activity and malondialdehyde (MDA) measurement to indicate the oxidative damage caused by $\mathrm{CB}$, single-wall carbon nanotube, $\mathrm{SiO}_{2}$ and $\mathrm{ZnO}$ NPs. The concentration of intracellular $\mathrm{GSH}$, determined by colorimetric assay, was also used by De Simone et al. [56] to evaluate the oxidative stress induced by cadmium-coated silica NPs. Alternatively, GSH depletion induced by silver NPs in HepG2 cells was evaluated through luminescence measurement using a plate reader [88].

In another study, despite the measurement of intracellular GSH, it was performed specific assays to determine the activities of glutathione reductase (GR) and glutathione peroxidase (GPx), two crucial enzymes involved in GSH metabolism [89]. The results of each assay were obtained through spectrophotometric readings.

The measurement of reactive nitrogen species (RNS) have also been used to determine oxidative stress induced by NMs. Roy et al. [90] applied this assay to measure the RNS generation after machophages incubation with ZnO NPs. After a defined incubation time, RNS was measured by using Griess's reagent and absorbance was measured at $540 \mathrm{~nm}$ in a plate reader.

Superoxide anion production induced by plant latex-capped silver NPs was evaluated by nitro blue tetrazolium (NBT) reduction method [82]. The results were obtained after absorbance readings at $570 \mathrm{~nm}$.

The reaction of malondialdehyde (MDA) with thiobarbituric acid (TBA) has been applied to determine the lipid peroxidation elicited by ROS. It is known that cell surface and organelle membrane lipids may undergo peroxidation in response to oxidative stress [91]. In this line, the oxidative damage induced by nanovesicles containing $\mathrm{pH}$-sensitive surfactants was studied by using this simple approach, being the responses measured using a microplate reader at $532 \mathrm{~nm}$ [20]. The measurement of MDA was also used by Tang et al. [92] to determine the oxidative stress induced by nanosized titanium dioxide.

\subsection{Induction of Injury in Specific Cell Organelles: Mitochondria and Lysosome}

\subsubsection{Mitochondrial Injury}

The mitochondrial injury has been commonly evaluated by the rhodamine 123 (R123) assay, which is based on fluorometric readings of cell responses after incubation with the NMs under test. Sahu et al. [53] used this approach to assess the induction of any damage to the mitochondria after cell treatment with silver NPs. The uptake and retention of the fluorescent dye R123 by viable living cells is directly proportional to their mitochondria membrane potential [93] and thus any injury in the mitochondrial compartment will be detected by alteration in this potential.

This same approach was used to assess the effect of $\mathrm{TiO}_{2} \mathrm{NPs}$ on the mitochondrial integrity, the cells being re-suspended in PBS containing $25 \mathrm{mM}$ rhodamine 123 after each NP treatment [37]. 
Whereas many authors use the ATP luminescence assay to detect NM cytotoxicity, Tang et al. [92] applied this assay as a measure of mitochondrial integrity. Intracellular ATP level is a sensitive readout of the mitochondrial state and was determined using a firefly luciferase-based ATP assay.

Tetramethyl rhodamine ethyl ester (TMRE) assay has been applied to measure the mitochondrial membrane potential (MMP) after NM treatment. Chairuangkitti et al. [79] evaluated the changes in the MMP after silver NPs exposure by using the TMRE assay. TMRE is a red-orange fluorescent permeable cationic and lipophilic dye, which can be readily taken up by active mitochondria into the negatively charged mitochondrial matrix. Thus, the intensity of the fluorescent signal obtained is indicative of the MMP. In another study, changes in the MNP, after cell incubation with titanium dioxide NPs, were measured using the lipophilic cationic dye, 3,3'-dihexyloxacarbocyanine ( DiOC $_{6}$ ), with cell analysis performed by flow cytometry [94].

\subsubsection{Lysosomal Injury}

The integrity of the lysosomal membrane after cell treatment with $\mathrm{pH}$-sensitive chitosan NPs encapsulating methotrexate (MTX) has been assessed using the acridine orange (AO) relocation technique [7]. AO is a lysosomotropic base that produces a red fluorescent emission when accumulated in acidic lysosomes, and the disruption of the lysosomal membrane can be assessed by measuring the change in intracellular $\mathrm{AO}$ fluorescence (i.e., the loss of the lysosomal red signal and gain of cytoplasmic green) (Figure 4). Following the treatment with NPs, the cells were stained with the dye and analyzed under fluorescence microscopy.

Figure 4. Assessment of the effects of chitosan NPs encapsulating MTX (MTX-CS-NPs) on lysosomal membrane permeabilization in HeLa cells as visualized via AO staining. In untreated control cells, lysosomes can be seen as red-orange granules and cytoplasm has a diffuse green fluorescence. In cells with lysosomal membrane damage (HeLa cells treated with $50 \mathrm{mg} / \mathrm{mL}$ MTX-CS-NPs), lysosomes exhibit a shift from red-orange to a yellow-green fluorescent color. Reprinted with permission from [7]. Copyright 2013, Elsevier.
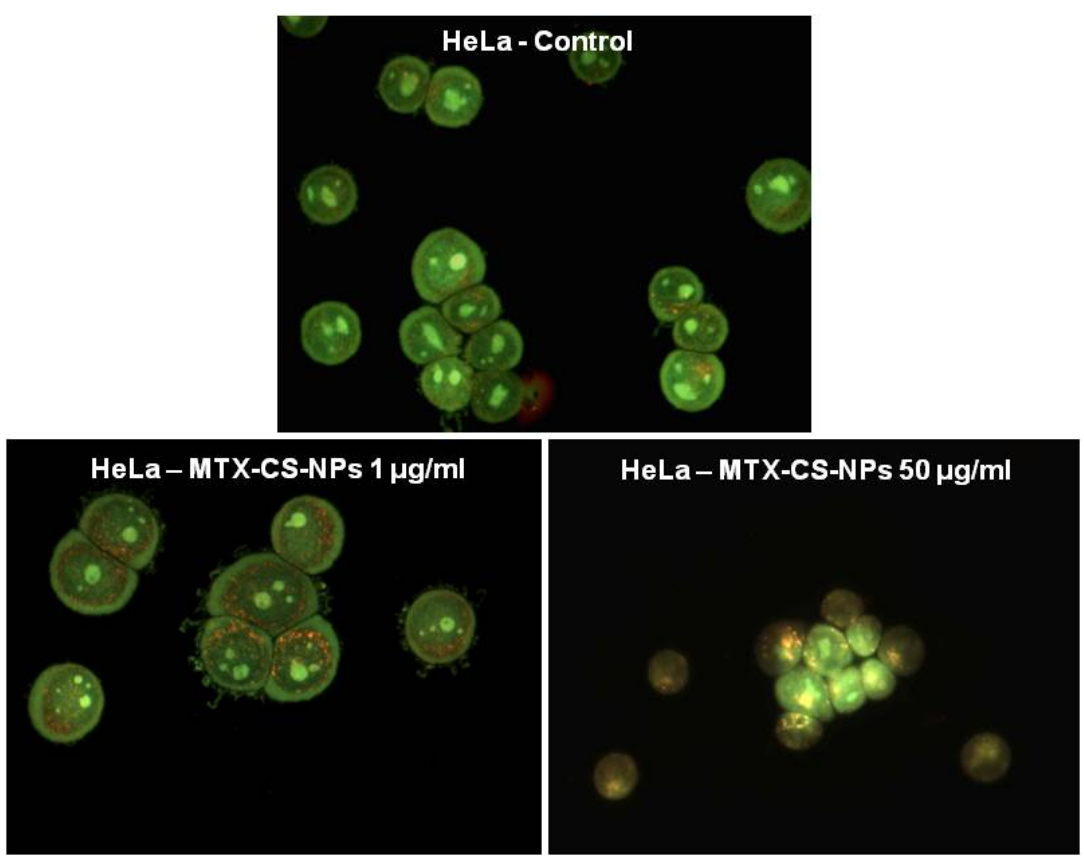
Sohaebuddin et al. [95] also applied this same assay to determine the effects of $\mathrm{TiO}_{2}$ and $\mathrm{SiO}_{2} \mathrm{NPs}_{\text {, and }}$ multi-wall carbon nanotubes (MWCNTs) with differing sizes, on lysosomal membrane integrity of three established cell lines. In another study, the effect of the polystyrene nanosphere on lysosomal stability was determined by using AO staining, but with cell analysis performed by flow cytometry [41].

Alternatively, Fröhlich et al. [96] used lucifer yellow to assess the lysosomal integrity after cell exposure to polystyrene NPs of different sizes, the results being obtained after analysis by confocal laser scanning microscopy. Moreover, the authors used an acidotropic probe that accumulates in acidic compartments of cells as a result of protonization to assess the lysosome function $/ \mathrm{pH}$. Accumulation in the acidic environment of lysosomes results in a $\mathrm{pH}$-dependent increase in fluorescence, which was quantified by confocal laser scanning microscopy. Finally, the lysosome function was also assessed by measuring the activity of lysosomal enzymes cathepsin B and sulfatases through fluorometry.

\subsection{Induction of DNA Damage and Genotoxicity}

The alkaline single-cell gel electrophoresis (comet) assay has been used to study DNA strand breaks and alkaline labile sites in different cell lines after NM treatment. This assay was performed to assess the genotoxicity potential of different types of NMs, including $\mathrm{CB}$, single-wall carbon nanotube, $\mathrm{SiO}_{2}$ and $\mathrm{ZnO}$ NPs [19]. Moreover, Khatri et al. [80] used this assay to assess the DNA damage prompted by photocopiers emittinh NPs, while Ghosh et al. [37] monitored the DNA damage in human lymphocytes incubated with $\mathrm{TiO}_{2}$ NPs (Figure 5), and Nogueira et al. [20] assessed the genotoxic potential of $\mathrm{pH}$-sensitive lipid-based nanovesicles.

Figure 5. Comet data ( $\%$ tail DNA) of human lymphocytes treated with different concentrations of titanium dioxide $\left(\mathrm{TiO}_{2}\right)$ nanoparticle; $* P<0.05$. Reprinted with permission from [37]. Copyright 2013, John Wiley and Sons.

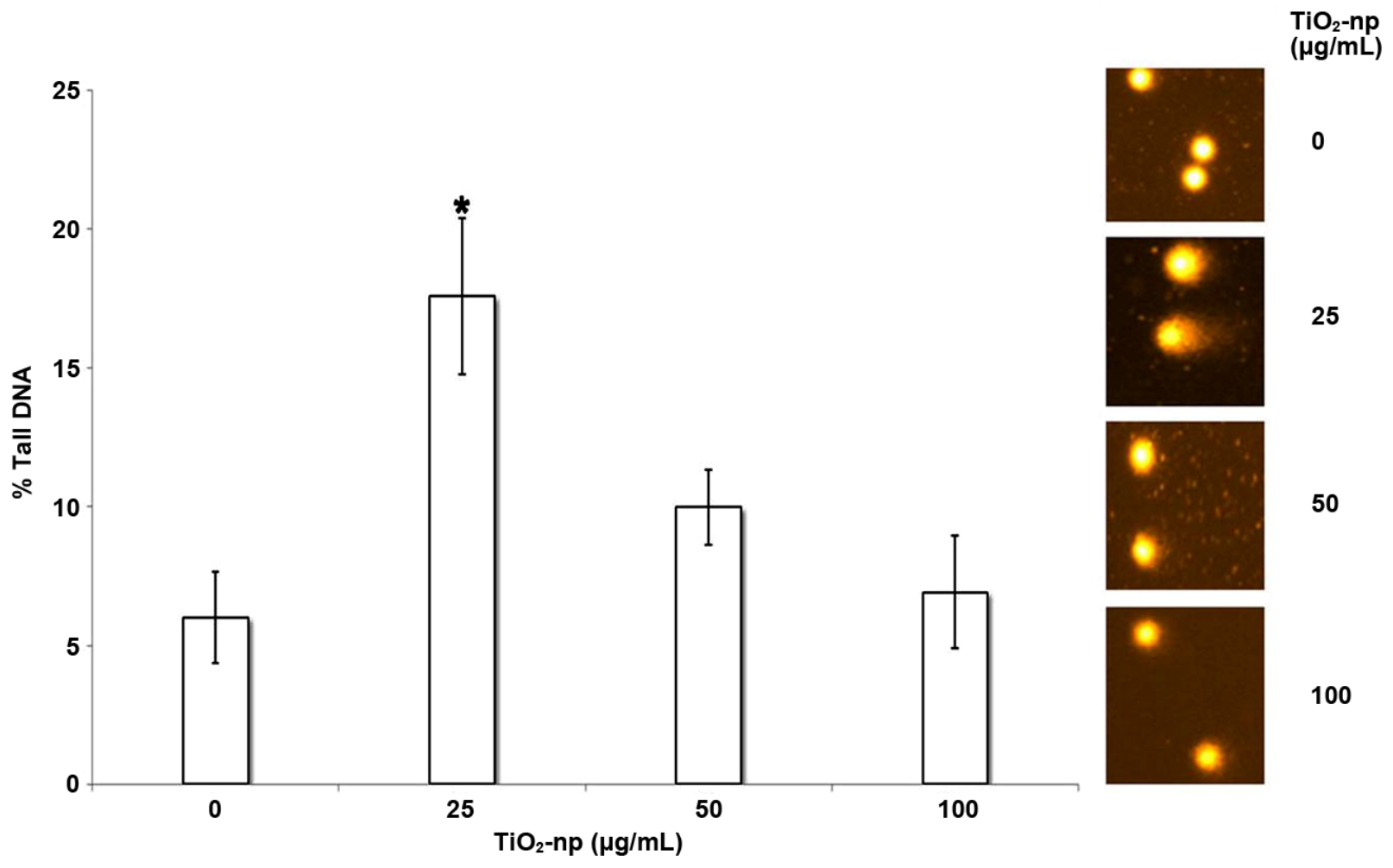


Cellular DNA damage induced by silver NPs was determined fluorometrically by the cellular double-stranded DNA (ds-DNA) content. In this assay, the nonfluorescent dye Hoechst 33258 becomes highly fluorescent when it binds to the ds-DNA, the ds-DNA content being determined from a standard plot [53].

Genotoxicity of PVP-coated silver NPs in BEAS 2B cells was assessed by three different approaches: the alkaline comet assay, the chromosomal aberration (CA) assay, and the cytokinesis-block micronucleus (CBMN) assay [48], which can be used to study chromosomal damage that occurs due to exposure to toxic agents.

The in vitro DNA damage induction by short multi- and single-wall carbon nanotubes was assessed by comet assay, by the CBMN assay and also by using the immunoslot blot assay for the detection of malondialdehyde (M1dG) DNA adducts [97].

Finally, detection of genotoxicity induced by mesoporous silicon NPs was made using the BrdU (5-bromo-20-deoxyuridine) ELISA-based assay [98]. The results were obtained after absorbance measuring using a microplate reader at a wavelength of $450 \mathrm{~nm}$.

\subsection{Inflammatory Responses}

Enzyme-linked immunosorbent assay (ELISA) is the main method used to measure the inflammatory responses of different kinds of NMs. The conditioned medium of HSCs cells treated with silver NPs were analyzed using ELISA for the presence of different mediators, such as hepatocyte growth factor (HGF), interleukin (IL)-6, transforming growth factor (TGF)- $\beta 1$, tumor necrosis factor (TNF)- $\alpha$, matrix metallopeptise (MMP)-2 and MMP-9 [46]. An ELISA kit was also used to quantify the levels of the proinflammatory IL-8 after cell treatment with ZnO NPs [99].

The measurement of enhancement in secretions of cytokines, in particular proinflammatory cytokines, following the incubation of cells with NPs coated with either non-ionic poly(ethylene glycol) or zwitterionic poly(carboxybetaine), was performed by using a multiplex assay that monitor the expression of several cytokines, including interleukin (IL)-1 $\alpha$, IL-1 $\beta$, IL-2, IL-3, IL-4, IL-5, IL-6, IL-9, IL-10, IL-12 (P40), IL-12 (P70), IL-13, IL-17, granulocyte-colony-stimulating factor(G-CSF), granulocyte macrophage-colony-stimulating factor (GM-CSF), interferon- $\gamma$ (IFN- $\gamma$ ) and tumor necrosis factor- $\alpha$ (TNF- $\alpha)$ [100]. Likewise, a multiplex assay was used to assess the release of 13 cytokines (IL-8, G-CSF, IL-1 $\alpha$, IL-1 $\beta$, IL-6, IFN $\gamma$, and others) after THP-1 cells treatment with photocopiers emitting NPs [80].

In another study, cytokines such as IL-12, TNF- $\alpha$, IL-10, IL-6, IL-1 $\beta$ and IL- 8 were measured by a cytometric beads array set system, the samples being incubated with antibodies for fluorescence detection and analyzed by flow cytometry [51]. This assay was applied to assess the inflammatory response induced by multi-walled carbon nanotubes. Likewise, Roy et al. [90] used this approach to measure IL-6, IL-10, IL-17, TNF- $\alpha$ and IFN- $\gamma$ release after cell treatment with ZnO NPs. Moreover, these same authors also examined the role of proteins opsonization of $\mathrm{ZnO}$ NPs with IgG in phagocytosis. With this intend, fetal bovine serum (FBS) opsonized particles (ZnO NPs disperse in 10\% FBS-supplemented RPMI (Roswell Park Memorial Institute) media) were incubated with IgG and its binding was measured by ELISA. 
Lastly, elastase release assay was also used to measure inflammation because activated neutrophils degranulate to release inflammatory mediators such as elastase. This assay was applied to evaluate the response of human neutrophil after exposure to cationic surfactants in the form of NPs and micelles [50].

\subsection{Interactions with Blood Components}

Hemolysis and agglutination assays using EDTA-stabilized rat blood were performed to determine the hemocompatibility of lipid nanovesicles modified with cationic lysine-based $\mathrm{pH}$-sensitive surfactants [20]. For the typical hemolysis assay, the samples were incubated with erythrocyte suspension, the measure of cell damage and hemoglobin release having been performed by spectrophotometry. On the other hand, the agglutination was determined by phase contrast microscopy. In this same study, the authors also analyzed the adsorption of human plasma proteins to the surface of the nanocarriers. For this purpose, sodium dodecyl sulfate polyacrylamide gel electrophoresis (SDS-PAGE) analysis was performed. These same hemolysis and agglutination assays were also used by the authors to determine the blood compatibility of chitosan NPs modified with a pH-sensitive lysine-based anionic surfactant [7].

Hemolysis assay was also employed to evaluate the in vitro blood compatibility of GO and GS intended for biomedical applications, using fresh ethylenediaminetetraacetic acid (EDTA)-stabilized human whole blood samples [38]. Recently, Shahbazi et al. [98] performed the hemolysis assay using human erythrocytes to study the hemocompatibility of mesoporous silicon NPs. Moreover, to evaluate the morphological changes and also the NP-erythrocyte interactions, the diluted erythrocyte suspension were evaluated by scanning electron microscopy (SEM) after incubation with NPs.

An extended study on the effects of $\mathrm{TiO}_{2}$ NPs on peripheral blood has been performed by Ghosh et al. [37]. Human peripheral blood cells were incubated with different concentrations of NPs and blood count tests were performed using a hematology analyzer to determine, among other parameters, the white and red blood cell count, hemoglobin, hematocrit value, platelet count, neutrophils, lymphocyte, monocyte, eosinophil, basophil and reticulocytes.

It is known that NPs are subject to the inspection of the immune system and, the complement system is a rapid-acting host defense mechanism that protects the intravascular space and other biological compartments from foreign attackers [101]. In this context, Pham et al. [102] employed a modified in vitro hemolysis-based assay to examine the variations in NP-mediated complement activity between individuals. The assay was applied to perfluorocarbon NPs of varying size, charge and surface chemistry, and might provide the tools for an in-depth structure-activity relationship study.

Hyperbranched polyglycerol hybrid nanostructures were tested for their probable effects on blood coagulation time by using Prothrombin Time (PT) and Activated Partial Thromboplastin Time (APTT) tests, the blood biocompatibility of NMs being measured by means of a coagulation analyzer with mechanical end point determination [103]. Moreover, the complement activation was evaluated using a commercial single radial immuno-diffusion (SRID) immunoassay kit, which monitors the cleavage of complement components $\mathrm{C} 3$ and $\mathrm{C} 4$. 


\section{Nanomaterials Characterization Needed for Reliable Nanotoxicological Assessment}

In vitro nanotoxicology has many advantages (as already described in Section 2), but also presents special problems that are directly related to the specific characteristics and physicochemical properties of NMs. Not everything called nano is actually nano, because secondary structures with significantly higher sizes are formed due to NP agglomeration or aggregation in aqueous media [104]. Nanoparticle size is a significant parameter to evaluate, not only in determining the release profile and degradation manners, but also in determining the efficacy of the therapeutic agent in terms of tissue penetration and cellular uptake [105]. This is only one example that highlights the importance of a detailed physicochemical characterization before the performance of any in vitro study. Structural alterations of NPs in aqueous solutions, i.e., in cell-culture medium, might also affect and change the final results of the in vitro toxicological studies. Likewise, the surface charge of NPs plays an especially important role in cell-NP interactions because cell membranes themselves are charged [38]. Understanding the behavior of NMs at the time of toxicological assay may play a crucial role in the interpretation of its results [106]. Finally, the results obtained from studies in which the NM characterization was not properly performed might be very controversial, making difficult the gain of conclusive data and the elucidation of the main mechanisms underlying toxicity.

Nanoparticles with similar chemical compositions may have totally different sizes, shapes, crystal structures, surface coatings, and surface reactivity characteristics, thereby creating a quite difficult situation for analysis by chemists, medical scientists and toxicologists [10]. Therefore, a detailed and comprehensive physicochemical characterization of the test NMs is stated as the first step before any toxicological screening [2,15].

A testing system to assess NM toxicity has been suggested [23,29]. Different stages are described, including an emphasis on detailed physicochemical characterization prior to and during subsequent testing in cell-free, in vitro cell-based and in vivo assays. The careful evaluation of NM solubility, chem-reactivity, size, hydrodynamic diameter, agglomeration/aggregation, zeta potential and polydispersity is recommended.

The unique physiochemical properties of NMs might represent major problems during in vitro assays. Even the utilization of well-established in vitro models can lead to false-positive or false-negative results, as well confounding or conflicting data. Furthermore, the properties of NMs, such as nanosize, high absorption capacity, catalytic activity, magnetic properties, dissolution and alkalinity/acidity, might introduce substances into cytotoxicity studies, which could interfere with assay components or detection systems [107]. Taken together, these unique characteristics of NMs must be considered for their in vitro toxicological evaluation. Because of the predicted variability and inconclusive data, a combination of different techniques and endpoint assays might be required in order to achieve more reliable data about NM risk assessment.

A suitable characterization of NMs, either in the original dispersion or when suspended in cell culture media, is needed prior to any in vitro assay in order to achieve detailed knowledge concerning general and specific bio-nano interactions. Size characterization can be performed by scanning electron microscopy (SEM) [108,109] or transmission electron microscopy (TEM) [31,48,110]. Dynamic light scattering (DLS) is widely used to determine the hydrodynamic diameter and the polidispersity of NM suspensions [20,111]. Other less conventional methods have also been applied to 
size characterization of NMs. Helfrich et al. [112] developed a reliable method for the size characterization of gold NPs by using liquid chromatography coupled on-line to inductively coupled plasma-mass spectrometry (ICP-MS). Surface morphology and particle size of the NPs can be also determined by atomic force microscopy (AFM), as described by Paul et al. [34] to characterize PLGA NPs. Liao et al. [38] also used AFM to measure the particle size of graphene sheets (GS) and graphene oxide (GO).

Izak-Nau et al. [106] performed a detailed characterization of silica NPs by assessing their colloidal stability in water, standard biological buffers, and cell culture media containing either bovine or human sera. Techniques such as DLS, zeta potential measurements and TEM have also been used. Moreover, interactions of the particles with biological media were investigated by SDS-PAGE in bovine and human sera, and extracted proteins were assessed using matrix-assisted laser desorption/ionization-time of flight technique (MALDI-TOF). The authors demonstrated that the NPs tended to agglomerate, and that this phenomenon depended on NP functionalization as well as on their concentration and the incubation time. Altogether, the results of this study showed that the surface charge, ionic strength and biological molecules alter the properties of NPs and potentially affect their resulting biological effects.

For the polymeric NPs, Fourier transform infrared (FTIR) spectroscopic studies to ascertain whether the encapsulation procedure altered the characteristics of polymer or drug, and whether interactions occur between the drug and the polymer after encapsulation is very commonly applied. Furthermore, FTIR data also speak about whether appropriate polymerization had occurred or whether monomers were present in the physical mixture. Among many authors, Paul et al. [34] characterized chelidonine-loaded PLGA NPs by using this analytical approach. Likewise, attenuated total reflectance-FTIR spectroscopy has been applied to evaluate the attachment of a reducing and stabilizing agent to silver NPs [98]. Moreover, in this same study, the kinetics of thermal decomposition of the nanocomposites was investigated using different heating rate thermo-gravimetric analysis.

More specifically, information about the molecular structure and chemical speciation can be obtained using techniques such as synchrotron radiation circular dichroism spectroscopy (SRCD) and X-ray absorption fine structure (XAFS), respectively [10]. X-ray photoelectron spectroscopy (XPS) was also used to measure the chemical composition of NMs such as GO and GS [38]. Moreover, Raman spectroscopy is a noninvasive technique that can be applied for the characterization of structural and electronic properties of NMs [113,114].

Information concerning the specific surface area per mass unit $\left(\mathrm{m}^{2} \cdot \mathrm{g}^{-1}\right)$ has been obtained by means of Brunauer, Emmet and Teller (BET) analysis (adsorption of nitrogen in cryogenic condition). The surface area is an important type of metric to be considered during toxicological studies and, thus, the BET analysis has been applied to characterize NMs such as silica NPs [115], nanoclusters of poorly soluble drugs [116], and calcium carbonate NPs [117].

\section{Relationships between Cell Internalization of Nanomaterials and Their Toxicological Responses}

The varied NM-cellular localization and interaction might lead to varied modes of toxicity. Even NPs of the same material can show completely different intracellular behavior due to, for example, 
slight differences in surface coating, charge and size. It has been reported that especially the NM size determines the efficiency of cellular uptake and subsequent intracellular processing [118].

Cellular uptake and localization of NPs will almost certainly be different than internalization of molecular species, and this fact will likely lead to different modes of toxicity. While there are some examples in the literature exploring NP uptake and localization, this is currently far from being well understood and, evidently varies significantly based on the NP being used. In order to obtain more reliable data concerning cellular uptake and localization, a number of imaging methods are available to greatly advance the understanding of NM behavior in the cellular compartments.

Not only the cell internalization, but also the disruption of the NM inside the cell greatly influences the resulting toxic effects. The cytotoxicity could be attributed to the chemical composition of the nanostructure, but it should be considered that the NM destabilization results in release of its content into intracellular compartments, which can present synergic cytotoxic effects. This cytotoxicity can be desired, i.e., in antitumor treatments [7,119,120], or undesired, i.e., during NM application for diagnostics purposes [121,122].

The internalization efficiency of NMs is commonly assessed by using flow cytometry and/or fluorescent microscopy. For this purpose, a range of different dyes have been using in order to control and/or visualize the intracellular trafficking and final localization of NPs. Rhodamine [123], FITC [41] and acridine orange [124] are molecules usually used as fluorescent markers in this kind of study. Considering the drugs with autofluorescent behavior, doxorubicin is the most commonly used as model molecule $[125,126]$.

When the NM is designed for an intended release of its content inside the cell in order to achieve therapeutic effects, one common strategy is to exploit the intracellular pH gradients [127]. Fluorescent dyes and drugs are frequently used as markers for cell uptake and intracellular behavior studies. Among fluorescent dyes, calcein has been widely applied as a tracer molecule, which is internalized by the cell through endocytosis and is thus used to monitor the stability of endosomes following NM uptake [7,20].

Cellular visualization of NPs can be assessed through analytical approaches such as fluorescence microscopy, flow cytometry, confocal laser scanning microscopy (CLSM), transmission electron microscopy (TEM), soft X-ray scanning transmission microscopy (STXM), X-ray fluorescence $(\mu$-XRF) and X-ray absorption near edge structure ( $\mu$-XANES) [10]. Additionally, Ng et al. [128] demonstrated the applicability of Energy-Dispersive X-ray (EDX) spectroscopy to reveal cellular uptake of gold NPs and their aggregate forms. Likewise, inductively coupled optical emission spectrometry (ICP-OES) was used to determine the cellular uptake of cadmium NPs in renal cells [36]. Moreover, inductively coupled plasma-mass spectrometer (ICP-MS) has been applied to measure the intracellular content of silver NPs [88].

\section{Conclusions}

Nanotechnology is considered a technology of the future, with especially important potential applications in the biomedical sciences. Nanotechnology, nanomedicine and nanotoxicology are complementary fields that in conjunction aim to improve human life. The discipline of nanotoxicology aims to study how properties of NMs define their interactions with cells, tissues and organs in exposed 
humans. In this context, understanding NM behavior in live biological systems is of increasing importance for determining their potential toxicity.

The need for more toxicological information concerning the risks of exposure to nano-based structures is reflected in the growing number of studies leaning toward the evaluation of NM toxicity and elucidation of the mechanisms underlying these hazardous effects to environmental and human health. The in vitro cell-based approaches are more attractive for NM testing, especially due to ethical aspects and the expense of animal testing. Therefore, relevant in vitro toxicological models based on established cell lines have become the basis of a highly needed screening approach and high-throughput toxicity testing protocols essential for the preliminary risk assessment of NMs. In line with the in vitro toxicology, it is worth mentioning that all toxicity data must be interpreted in the context of the physicochemical characteristics of the nano-sized materials, in order to assure the reliability of the obtained data, and also to possibly establish a structure-toxicity relationship.

\section{Acknowledgments}

This study was supported by Projects MAT2012-38047-C02-01 of the Ministerio de Economía $y$ Competitividad (Spain) and 483264/2012-1 of the Conselho Nacional de Desenvolvimento Cientifico e Tecnológico $(\mathrm{CNPq}$ - Brazil). Daniele Rubert Nogueira holds a postdoctoral fellowship from PNPD-CAPES (Brazil).

\section{Author contributions}

The authors have made equal contributions in the preparation of this review.

\section{Conflicts of Interest}

The authors declare no conflict of interest.

\section{References and Notes}

1. Hartung, T. Food and thought...on alternative methods for nanoparticle safety testing. ALTEX 2010, 27, 87-95.

2. Horie, M.; Kato, H.; Fujita, K.; Endoh, S.; Iwahashi, H. In vitro evaluation of cellular response induced by manufactured nanoparticles. Chem. Res. Toxicol. 2012, 25, 605-619.

3. Paillard, A.; Hindré, F.; Vignes-Colombeix, C.; Benoit, J.-P.; Garcion, E. The importance of endo-lysosomal escape with lipid nanocapsules for drug subcellular bioavailability. Biomaterials 2010, 31, 7542-7554.

4. Singh, R.; Lillard, J.W., Jr. Nanoparticle-based target drug delivery. Exp. Mol. Pathol. 2009, 86, 215-223.

5. Sahoo, S.K.; Parveen, S.; Panda, J.J. The present and future of nanotechnology in human health care. Nanomedicine 2007, 3, 20-31.

6. Parveen, S.; Sahoo, S.K. Polymeric nanoparticles for cancer therapy. J. Drug Target. 2008, 16, $108-123$. 
7. Nogueira, D.R.; Tavano, L.; Mitjans, M.; Pérez, L.; Infante, M.R.; Vinardell, M.P. In vitro antitumor activity of methotrexate via $\mathrm{pH}$-sensitive chitosan nanoparticles. Biomaterials 2013, 34, 2758-2772.

8. $\quad$ Robbens, J.; Vanparys, C.; Nobels, I.; Blust, R.; Hoecke, K.V.; Janssen, C.; Schamphelaere, K.D.; Roland, K.; Blanchard, G.; Silvestre, F.; et al. Eco-, geno-, and human toxicology of bio-active nanoparticles for biomedical applications. Toxicology 2010, 269, 170-181.

9. Donaldson, K.; Stone, V.; Tran, C.L.; Kreyling, W.; Borm, P.J.A. Nanotoxicology. Occup. Environ. Med. 2004, 61, 727-728.

10. Chen, C.; Li, Y.F.; Qu, Y.; Chai, Z.; Zhao, Y. Advanced nuclear analytical and related techniques for the growing challenges in nanotoxicology. Chem. Soc. Rev. 2013, 42, 8266-8303.

11. Oberdörster, G.; Stone, V.; Donaldson, K. Toxicology of nanoparticles: A historical perspective. Nanotoxicology 2007, 1, 1-25.

12. Borm, P.J.A.; Robbins, D.; Haubold, S.; Kuhlbusch, T.; Fissan, H.; Donaldson, K.; Schins, R.; Stone, V.; Kreyling, W.; Lademann, J.; et al. The potential risks of nanomaterials: A review carried out for ECETOC. Part. Fibre Toxicol. 2006, 3, 11.

13. Savolainen, K.; Alenius, H.; Norppa, H.; Pylkkänen, L.; Tuomi, T.; Kasper, G. Risk assessment of engineered nanomaterials and nanotechnologies-A review. Toxicology 2010, 269, 92-104.

14. Winkler, D.A.; Mombelli, E.; Pietroiusti, A.; Tran, L.; Worth, A.; Fadeel, B.; McCall, M.J. Applying quantitative structure-activity relationship approaches to nanotoxicology: Current status and future potential. Toxicology 2013, 313, 15-23.

15. Boverhof, D.R.; David, R.M. Nanomaterial characterization: Considerations and needs for hazard assessment and safety evaluation. Anal. Bioanal. Chem. 2010, 396, 953-961.

16. REACH (Registration, Evaluation, Authorisation and Restriction of Chemical substances), Regulation (EC) No 1907/2006 of the European Parliament and of the Council, of 18 December 2006.

17. Clark, K.A.; White, R.H.; Silbergeld, E.K. Predictive models for nanotoxicology: Current challenges and future opportunities. Regulatory Toxicol. Pharmacol. 2011, 59, 361-363.

18. Ai, J.; Biazar, E.; Jafarpour, M.; Montazeri, M.; Majdi, A.; Aminifard, S.; Zafari, M.; Akbari, H.R.; Rad, H.G. Nanotoxicology and nanoparticle safety in biomedical designs. Int. J. Nanomed. 2011, 6, 1117-1127.

19. Yang, H.; Liu, C.; Yang, D.; Zhang, H.; Xi, Z. Comparative study of cytotoxicity, oxidative stress and genotoxicity induced by four typical nanomaterials: The role of particle size, shape and composition. J. Appl. Toxicol. 2009, 29, 69-78.

20. Nogueira, D.R.; Morán, M.C.; Mitjans, M.; Pérez, L.; Ramos, D.; de Lapuente, J.; Vinardell, M.P. Lysine-based surfactants in nanovesicle formulations: The role of cationic charge position and hydrophobicity in in vitro cytotoxicity and intracellular delivery. Nanotoxicology 2014, 8, 404-421.

21. Hillegass, J.M.; Shukla, A.; Lathrop, S.A.; MacPherson, M.B.; Fukagawa, N.K.; Mossman, B.T. Assessing toxicity in cells in vitro. WIREs Nanomed. Nanotechnol. 2009, 2, 219-231.

22. Jones, C.F.; Grainger, D.W. In vitro assessments of nanomaterial toxicity. Adv. Drug Deliv. Rev. 2009, 61, 438-456. 
23. Oberdörster, G. Safety assessment for nanotechnology and nanomedicine: Concepts of nanotoxicology. J. Intern. Med. 2009, 267, 89-105.

24. Hartung, T. Food and thought...on cell culture. ALTEX 2007, 24, 143-147.

25. Monteiro-Riviere, N.A.; Inman, A.O.; Zhang, L.W. Limitations and relative utility of screening assays to assess engineered nanoparticle toxicity in a human cell line. Toxicol. Appl. Pharmacol. 2009, 234, 222-235.

26. Monteiro-Riviere, N.A.; Oldenburg, S.J.; Inman, A.O. Interactions of aluminum nanoparticles with human epidermal keratinocytes. J. Appl. Toxicol. 2010, 30, 276-285.

27. Hartung, T.; Leist, M. Food and thought...on the evolution of toxicology and phasing out of animal testing. ALTEX 2008, 25, 91-96.

28. Nyland, J.F.; Silbergeld, E.K. A nanobiological approach to nanotoxicology. Hum. Exp. Toxicol. 2009, 28, 393-400.

29. Oberdörster, G.; Maynard, A.; Donaldson, K.; Castranova, V.; Fitzpatrick, J.; Ausman, K.; Carter, J.; Karn, B.; Kreyling, W.; ILSI Research Foundation/Risk Science Institute Nanomaterial Toxicity Screening Working Group; et al. Principles for characterizing the potential human health effects from exposure to nanomaterials: Elements of a screening strategy. Part. Fibre Toxicol. 2005, 2, 8.

30. Guzelian, P.S.; Victoroff, M.S.; Halmes, C.; James, R.C. Clear path: Towards an evidence-based toxicology (EBT). Hum. Exp. Toxicol. 2009, 28, 71-79.

31. Nogueira, D.R.; Morán, M.C.; Mitjans, M.; Martínez, V.; Pérez, L.; Vinardell, M.P. New cationic nanovesicular systems containing lysine-based surfactants for topical administration: Toxicity assessment using representative skin cell lines. Eur. J. Pharm. Biopharm. 2013, 83, 33-43.

32. Ucciferri, N.; Collnot, E.-M.; Gaiser, B.; Tirella, A.; Stone, V.; Domenici, C.; Lehr, C.-M.; Ahluwalia, A. In vitro toxicological screening of nanoparticles on primary human endothelial cells and the role of flow in modulating cell respose. Nanotoxicology 2014, 8, 697-708.

33. Coulter, J.A.; Jain, S.; Butterworth, K.T.; Taggart, L.E.; Dickson, G.R.; McMahon, S.J.; Hyland, W.B.; Muir, M.F.; Trainor, C.; Hounsell, A.R.; et al. Cell type-dependent uptake, localization, and cytotoxicity of $1.9 \mathrm{~nm}$ gold nanoparticles. Int. J. Nanomed. 2012, 7, 2673-2685.

34. Paul, A.; Das, S.; Das, J.; Samadder, A.; Khuda-Bukhsh, A.R. Cytotoxicity and apoptotic signalling cascade induced by chelidonine-loaded PLGA nanoparticles in HepG2 cells in vitro and bioavailability of nano-chelidonine in mice in vivo. Toxicol. Lett. 2013, 222, 10-22.

35. Sambandam, B.; Palanisami, E.; Abbugounder, R.; Prakhya, B.; Thiyagarajan, D. Characterizations of coal fly ash nanoparticles and induced in vitro toxicity in cell lines. J. Nanopart. Res. 2014, 16, doi:10.1007/s11051-013-2217-x.

36. L’Azou, B.; Passagne, I.; Mounicou, S.; Tréguer-Delapierre, M.; Puljalté, I.; Szpunar, J.; Lobinski, R.; Ohayon-Courtès, C. Comparative cytotoxicity of cadmium forms $\left(\mathrm{CdCl}_{2}, \mathrm{CdO}\right.$, CdS micro- and nanoparticles) in renal cells. Toxicol. Res. 2014, 3, 32-41.

37. Ghosh, M.; Chakraborty, A.; Mukherjee, A. Cytotoxic, genotoxic and the hemolytic effect of titanium dioxide $\left(\mathrm{TiO}_{2}\right)$ nanoparticles on human erythrocyte and lymphocyte cells in vitro. J. Appl. Toxicol. 2013, 33, 1097-1110. 
38. Liao, K.-H.; Lin, Y.-S.; Macosko, C.W.; Haynes, C.L. Cytotoxicity of graphene oxide and graphene in human erythrocytes and skin fibroblasts. ACS Appl. Mater. Interfaces 2011, 3, 2607-2615.

39. Berridge, M.V.; Herst, P.M.; Tan, A.S. Tetrazolium dyes as tools in cell biology: New insights into their cellular reduction. Biotechnol. Annu. Rev. 2005, 11, 127-152.

40. Chueh, P.J.; Lianga, R.-Y.; Leea, Y.-H.; Zenga, Z.-M.; Chuanga, S.-M. Differential cytotoxic effects of gold nanoparticles in different mammalian cell lines. J. Hazard. Mat. 2014, 264, 303-312.

41. Xia, T.; Kovochich, M.; Liong, M.; Zink, J.I.; Nel, A.E. Cationic polystyrene nanosphere toxicity depends on cell-specific endocytic and mitochondrial injury pathways. ACS Nano 2008, 2, 85-96.

42. Ojer, P.; Neutsch, L.; Gabor, F.; Irache, J.M.; de Cerain, A.L. Cytotoxicity and cell interaction studies of bioadhesivepoly(anhydride) nanoparticles for oral antigen/drug delivery. J. Biomed. Nanotechnol. 2013, 9, 1891-1903.

43. Vetten, M.A.; Tlotleng, N.; Rascher, D.T.; Skepu, A.; Keter, F.K.; Boodhia, K.; Koekemoer, L.A.; Andraos, C.; Tshikhudo, R.; Gulumian, M. Label-free in vitro toxicity and uptake assessment of citrate stabilised gold nanoparticles in three cell lines. Part. Fibre Toxicol. 2013, 10, 50.

44. Ha, S.-W.; Sikorski, J.A.; Weitzmann, M.N.; Beck, G.R., Jr. Bio-active engineered 50 nm silica nanoparticles with bone anabolic activity: Therapeutic index, effective concentration, and cytotoxicity profile in vitro. Toxicol. In Vitro 2014, 28, 354-364.

45. Foldbjerg, R.; Wang, J.; Beer, C.; Thorsen, K.; Sutherland, D.S.; Autrup, H. Biological effects induced by BSA-stabilized silica nanoparticles in mammalian cell lines. Chem. Biol. Interac. 2013, 204, 28-38.

46. Sun, X.; Wang, Z.; Zhai, S.; Cheng, Y.; Liu, J.; Liu, B. In vitro cytotoxicity of silver nanoparticles in primary rat hepatic stellate cells. Mol. Med. Rep. 2013, 8, 1365-1372.

47. Chuang, S.M.; Lee, Y.H.; Liang, R.Y.; Roam, G.D.; Zeng, Z.M.; Tu, H.F.; Wang, S.K.; Chueh, P.J. Extensive evaluations of the cytotoxic effects of gold nanoparticles. Biochim. Biophys. Acta 2013, 830, 4960-4973.

48. Nymark, P.; Catalán, J.; Suhonen, S.; Jarventaus, H.; Birkedal, R.; Clausen, P.A.; Jensen, K.A.; Vippola, M.; Savolainen, K.; Norppa, H. Genotoxicity of polyvinylpyrrolidone-coated silver nanoparticles in BEAS 2B cells. Toxicology 2013, 313, 38-48.

49. Karlsson, H.L.; Cronholm, P.; Hedberg, Y.; Tornberg, M.; de Battice, L.; Svedhem, S.; Wallinder, I.O. Cell membrane damage and protein interaction induced by copper containing nanoparticles-Importance of the metal release process. Toxicology 2013, 313, 59-69.

50. Hwang, T.-L.; Sung, C.T.; Aljuffali, I.A.; Chang, Y.-T.; Fang, J.-Y. Cationic surfactants in the form of nanoparticles and micelles elicit different human neutrophil responses: A toxicological study. Colloids Surf. B Biointerfaces 2014, 114, 334-341.

51. Haniu, H.; Saito, N.; Matsuda, Y.; Kim, Y.A.; Park, K.C.; Tsukahara, T.; Usui, Y.; Aoki, K.; Shimizu, M.; Ogihara, N.; et al. Elucidation mechanism of different biological responses to multi-walled carbon nanotubes using four cell lines. Int. J. Nanomed. 2011, 6, 3487-3497.

52. Darolles, C.; Sage, N.; Armengaud, J.; Malard, V. In vitro assessment of cobalt oxide particle toxicity: Identifying and circumventing interference. Toxicol. In Vitro 2013, 27, 1699-1710. 
53. Sahu, S.C.; Zheng, J.; Graham, L.; Chen, L.; Ihried, J.; Yourick, J.J.; Sprando, R.L. Comparative cytotoxicity of nanosilver in human liver HepG2 and colon Caco2 cells in culture. J. Appl. Toxicol. 2014, doi:10.1002/jat.2994.

54. Everett, W.N.; Chernb, C.; Suna, D.; McMahonb, R.E.; Zhanga, X.; Chenc, W.-J.A.; Hahn, M.S.; Sue, H.-J. Phosphate-enhanced cytotoxicity of zinc oxide nanoparticles andagglomerates. Toxicol. Lett. 2014, 225, 177- 184.

55. Demir, E.; Akça, H.; Kaya, B.; Burgucu, D.; Tokgün, O.; Turna, F.; Aksakal, S.; Vales, G.; Creus, A.; Marcos, R. Zinc oxide nanoparticles: Genotoxicity, interactions with UV-light and cell-transforming potential. J. Hazard Mater. 2014, 264, 420-429.

56. De Simone, U.; Manzo, L.; Profumo, A.; Coccini, T. In vitro toxicity evaluation of engineered cadmium-coated silica nanoparticles on human pulmonary cells. J. Toxicol. 2013, 2013, doi: $10.1155 / 2013 / 931785$.

57. Prodan, A.M.; Iconaru, S.L.; Ciobanu, C.S.; Chifiriuc, M.C.; Stoicea, M.; Predoi, D. Iron oxide magnetic nanoparticles: Characterization and toxicity evaluation by in vitro and in vivo assays. J. Nanomater. 2013, 2013, 587021:1-587021:10.

58. Tran, T.B.; Nguyen, P.D.; Um, S.H.; Son, S.J.; Min, J. Real-time monitoring in vitro cellular cytotoxicity of silica nanotubes using electric cell-substrate impedance sensing (ECIS). J. Biomed. Nanotechnol. 2013, 9, 286-290.

59. Zimmer, C.C.; Liu, Y.X.; Morgan, J.T.; Yang, G.; Wang, K.H.; Kennedy, I.M.; Barakat, A.I.; Liu, G.Y. New approach to investigate the cytotoxicity of nanomaterials using single cell mechanics. J. Phys. Chem. B 2014, 118, 1246-1255.

60. Frohlich, E.; Meindl, C.; Roblegg, E.; Griesbacher, A.; Pieber, T.R. Cytotoxicity of nanoparticles is influenced by size, proliferation and embryogenic origin of the cells used for testing. Nanotoxicology 2012, 6, 424-439.

61. Nogueira, D.R.; Mitjans, M.; Infante, M.R.; Vinardell, M.P. Comparative sensitivity of tumor and non-tumor cell lines as a reliable approach for in vitro cytotoxicity screening of lysine-based surfactants with potential pharmaceutical applications. Int. J. Pharm. 2011, 420, 51-58.

62. Schroterová, L.; Králová, V.; Vorácová, A.; Hascová, P.; Rudorlf, E. Antiproliferative effects of selenium compounds in colon cancer cells: Comparison of different cytotoxicity assays. Toxicol. In Vitro 2009, 23, 1406-1411.

63. Guadagnini, R.; Halamoda Kenzaoui, B.; Cartwright, L.; Pojana, G.; Magdolenova, Z.; Bilanicova, D.; Saunders, M.; Juillerat, L.; Marcomini, A.; et al. Toxicity screenings of nanomaterials: Challenges due to interference with assay processes and components of classic in vitro tests. Nanotoxicology 2013, doi:10.3109/17435390.2013.829590.

64. Hashimoto, M.; Hirokazu, T.; Yonezawa, T.; Kawai, K.; Iijima, M.; Endo, K. Evaluation of Silver Nanoparticle toxicity to RAW264.7 cells in a three-dimensional cell culture. J. Biomater. Tissue Eng. 2014, 4, 51-58.

65. Sanchez, V.C.; Weston, P.; Yan, A.; Hurt, R.H.; Kane, A.B. A 3-dimensional in vitro model of epithelioidgranulomas induced by high aspect rationanomaterials. Part Fibre Toxicol. 2011, 8, doi:10.1186/1743-8977-8-17. 
66. Gao, Y.; Li, M.; Chen, B.; Shen, Z.; Guo, P.; Wientjes, M.G.; Au, J.L. Predictive models of diffusive nanoparticle transport in 3-dimensional tumor cell spheroids. AAPS J. 2013, 15, 816-831.

67. El-Dakdouki, M.H.; Puré, E.; Huang, X. Development of drug loaded nanoparticles for tumor targeting. Part 2: Enhancement of tumor penetration through receptor mediated transcytosis in 3D tumor models. Nanoscale 2013, 5, 3904-3911.

68. Shi, W.-B.; Le, V.-M.; Gu, C.-H.; Zheng, Y.-H.; Lang, M.-D.; Lu, Y.-H.; Liu, J.-W. Overcoming multidrug resistance in $2 \mathrm{D}$ and $3 \mathrm{D}$ culture models by controlled drug chitosan-graft poly(caprolactone)-based nanoparticles. J. Pharm. Sci. 2014, 103, 1064-1074.

69. Xu, X.; Sabanayagam, C.R.; Harrington, D.A.; Farach-Carson, M.C.; Jia, X. A hydrogel-based tumor model for the evaluation of nanoparticle-based cancer therapeutics. Biomaterials 2014, 35, 3319-3330.

70. Rocha, E.L.; Porto, L.M.; Rambo, C.R. Nanotechnology meets 3D in vitro models: Tissue engineered tumors and cancer therapies. Mater. Sci. Eng. C 2014, 34, 270-279.

71. Šinko, G.; Vrček, I.V.; Goessler, W.; Leitinger, G.; Dijanošić, A.; Miljanić, S. Alteration of cholinesterase activity as possible mechanism of silver nanoparticle toxicity. Environ. Sci. Pollut. Res. 2014, 21, 1391-1400.

72. Wang, Z.; Zhao, J.; Li, F.; Gao, D.; Xing, B. Adsorption and inhibition of acetylcholinesterase by different nanoparticles. Chemosphere 2009, 77, 67-73.

73. Wang, Z.; Zhang, K.; Zhao, J.; Liu, X.; Xing, B. Adsorption and inhibition of butyrylcholinesterase by different engineered nanoparticles. Chemosphere 2010, 79, 86-92.

74. Ellman, G.L.; Courtney, K.D.; Andres, V.; Feather-stone, R.M. A new rapid colorimetric determination of acetylcholinesterase activity. Biochem. Pharmacol. 1961, 7, 88-95.

75. Deng, Z.J.; Butcher, N.J.; Mortimer, G.M.; Jia, Z.; Monteiro, M.J.; Martin, D.J.; Minchin, R.F. Interaction of human arylamine $N$-acetyltransferase 1 with different nanomaterials. Drug Metab. Dispos. 2014, 42, 377-383.

76. Käkinen, A.; Ding, F.; Chen, P.; Mortimer, M.; Kahru, A.; Ke, P.C. Interaction of firefly luciferase and silver nanoparticles and its impact on enzyme activity. Nanotechnology 2013, 24, 345101:1-345101:9.

77. Ciolkowski, M.; Rozanek, M.; Bryszewska, M.; Klajnert, B. The influence of PAMAM dendrimers surface groups on their interaction with porcine pepsin. Biochim. Biophys. Acta 2013, 1834, 1982-1987.

78. Wang, Y.; Zhang, X.; Cheng, C.; Li, C. Mucoadhesive and enzymatic inhibitory nanoparticles for transnasal insulin delivery. Nanomedicine 2014, 9, 541-464.

79. Chairuangkitti, P.; Lawanprasert, S.; Roytrakul, S.; Aueviriyavit, S.; Phummiratch, D.; Kulthong, K.; Chanvorachote, P.; Maniratanachote, R. Silver nanoparticles induce toxicity in A549 cells via ROS-dependent and ROS-independent pathways. Toxicol. In Vitro 2013, 27, 330-338.

80. Khatri, M.; Bello, D.; Pal, A.K.; Cohen, J.M.; Woskie, S.; Gassert, T.; Lan, J.; Gu, A.Z.; Demokritou, P.; Gaines, P. Evaluation of cytotoxic, genotoxic and inflammatory responses of nanoparticles from photocopiers in three human cell lines. Part. Fibre Toxicol. 2013, 10, 42. 
81. McCracken, C.; Zane, A.; Knight, D.A.; Dutta, P.K.; Waldman, W.J. Minimal intestinal epithelial cell toxicity in response to short- and long-term food-relevant inorganic nanoparticle exposure. Chem. Res. Toxicol. 2013, 26, 1514-1525.

82. Valodkar, M.; Jadeja, R.N.; Thounaojam, M.C.; Devkar, R.V.; Thakore, S. In vitro toxicity study of plant latex capped silver nanoparticles in human lung carcinoma cells. Mater. Sci. Eng. C 2011, 31, 1723-1728.

83. VanOs, R.; Lildhar, L.L.; Lehoux, E.A.; Beaulé, P.E.; Catelas, I. In vitro macrophage response to nanometer-size chromium oxide particles. J. Biomed. Mater. Res. B Appl. Biomater. 2014, 102, 149-159.

84. Yan, L.; Gu, Z.; Zhao, Y. Chemical mechanisms of the toxicological properties of nanomaterials: Generation of intracellular reactive oxygen species. Chem. Asian J. 2013, 8, 2342-2353.

85. Passagne, I.; Morille, M.; Rousset, M.; Pujalté, I.; L'azou, B. Implication of oxidative stress in size-dependent toxicity of silica nanoparticles in kidney cells. Toxicology 2012, 299, 112-124.

86. LeBlanc, A.J.; Moseley, A.M.; Chen, B.T.; Frazer, D.; Castranova, V.; Nurkiewicz, T.R. Nanoparticle inhalation impairs coronary microvascular reactivity via a local reactive oxygen species-dependent mechanism. Cardiovasc. Toxicol. 2010, 10, 27-36.

87. Shen, C.; James, S.A.; de Jonge, M.D.; Turney, T.W.; Wright, P.F.A.; Feltis, B.N. Relating cytotoxicity, zinc ions, and reactive oxygen in $\mathrm{ZnO}$ nanoparticle-exposed human immune cells. Toxicol. Sci. 2013, 136, 120-130.

88. Prasad, R.Y.; McGee, J.K.; Killius, M.G.; Suarez, D.A.; Blackman, C.F.; DeMarini, D.M.; Simmons, S.O. Investigating oxidative stress and inflammatory responses elicited by silver nanoparticles using high-throughput reporter genes in HepG2 cells: Effect of size, surface coating, and intracellular uptake. Toxicol. In Vitro 2013, 27, 2013-2021.

89. Akhtar, M.J.; Ahamed, M.; Kumar, S.; Siddiqui, H.; Patil, G.; Ashquin, M.; Ahmad, I. Nanotoxicity of pure silica mediated through oxidant generation rather than glutathione depletion in human lung epithelial cells. Toxicology 2010, 276, 95-102.

90. Roy, R.; Parashar, V.; Chauhan, L.K.; Shanker, R.; Das, M.; Tripathi, A.; Dwivedi, P.D. Mechanism of uptake of $\mathrm{ZnO}$ nanoparticles and inflammatory responses in macrophages require PI3K mediated MAPKs signaling. Toxicol. In Vitro 2014, 28, 457-467.

91. Choi, A.O.; Cho, S.J.; Desbarats, J.; Lovric, J.; Maysinger, D. Quantum dot-induced cell death involves Fas upregulation and lipid peroxidation in human neuroblastoma cells. J. Nanobiotechnol. 2007, 5,1 .

92. Tang, Y.; Wang, F.; Jin, C.; Liang, H.; Zhong, X.; Yang, Y. Mitochondrial injury induced by nanosized titanium dioxide in A549 cells and rats. Environ. Toxicol. Pharmacol. 2013, 36, 66-72.

93. Baracca, A.; Sgarbi, G.; Solaini, G.; Lenaz, G. Rhodamine 123 as a probe of mitochondrial membrane potential: Evaluation of proton flux through $\mathrm{F}(0)$ during ATP synthesis. Biochim. Biophys. Acta 2003, 1606, 137-146.

94. Kang, S.J.; Lee, Y.J.; Kim, B.M.; Choi, Y.J.; Chung, H.W. Cytotoxicity and genotoxicity of titanium dioxide nanoparticles in UVA-irradiated normal peripheral blood lymphocytes. Drug Chem. Toxicol. 2011, 34, 277-284. 
95. Sohaebuddin, S.; Thevenot, P.T.; Baker, D.; Eaton, J.W.; Tang, L. Nanomaterial cytotoxicity is composition, size, and cell type dependent. Part. Fibre Toxicol. 2010, 7, 22.

96. Fröhlich, E.; Meindl, C.; Roblegg, E.; Ebner, B.; Absenger, M.; Pieber, T.R. Action of polystyrene nanoparticles of different sizes on lysosomal function and integrity. Part. Fibre Toxicol. 2012, 9, 26.

97. Lindberg, H.K.; Falck, G.C.; Singh, R.; Suhonen, S.; Järventaus, H.; Vanhala, E.; Catalán, J.; Farmer, P.B.; Savolainen, K.M.; Norppa, H. Genotoxicity of short single-wall and multi-wall carbon nanotubes in human bronchial epithelial and mesothelial cells in vitro. Toxicology 2013, 313, 24-37.

98. Shahbazi, M.A.; Hamidi, M.; Mäkilä, E.M.; Zhang, H.; Almeida, P.V.; Kaasalainen, M.; Salonen, J.J.; Hirvonen, J.T.; Santos, H.A. The mechanisms of surface chemistry effects of mesoporous silicon nanoparticles on immunotoxicity and biocompatibility. Biomaterials 2013, 34, 7776-7789.

99. Hsiao, I.-L.; Huang, Y.-J. Effects of serum on cytotoxicity of nano- and micro-sized $\mathrm{ZnO}$ particles. J. Nanopart. Res. 2013, 15, 1829.

100. Elsabahy, M.; Li, A.; Zhang, F.; Sultan, D.; Liu, Y.; Wooley, K.L. Differential immunotoxicities of poly(ethylene glycol)- vs. poly(carboxybetaine)-coated nanoparticles. J. Control. Release 2013, 172, 641-652.

101. Ricklin, D.; Hajishengallis, G.; Yang, K.; Lambris, J.D. Complement: A key system for immune surveillance and homeostasis. Nat. Immunol. 2010, 11, 785.

102. Pham, C.T.N.; Thomas, D.G.; Beiser, J.; Mitchell, L.M.; Huang, J.L.; Senpan, A.; Hu, G.; Gordon, M.; Baker, N.A.; Pan, D.; et al. Application of a hemolysis assay for analysis of complement activation by perfluorocarbon nanoparticles. Nanomed. Nanotechnol. Biol. Med. 2013, doi:10.1016/j.nano.2013.10.012.

103. Zarrabi, A.; Shokrgozar, M.A.; Vossoughi, M.; Farokhi, M. In vitro biocompatibility evaluations of hyperbranched polyglycerol hybrid nanostructure as a candidate for nanomedicine applications. J. Mater. Sci. Mater. Med. 2014, 25, 499-506.

104. Holl, M.M.B. Nanotoxicology: A personal perspective. Wiley Interdiscip. Rev. Nanomed. Nanobiotechnol. 2009, 1, 353-359.

105. Gaumet, M.; Vargas, A.; Gurny, R.; Delie, F. Nanoparticles for drug delivery: The need for precision in reporting particlesize parameters. Eur. J. Pharm. Biopharm. 2008, 69, 1-9.

106. Izak-Nau, E.; Voetz, M.; Eiden, S.; Duschl, A.; Puntes, V.F. Altered characteristics of silica nanoparticles in bovine and human serum: The importance of nanomaterial characterization prior to its toxicological evaluation. Part. Fibre Toxicol. 2013, 10, 56.

107. Kroll, A.; Pillukat, M.H.; Hahn, D.; Schnekenburger, J. Current in vitro methods in nanoparticle risk assessment: Limitations and challenges. Eur. J. Pharm. Biopharm. 2009, 72, 370-377.

108. Kang, Y.; Wu, J.; Yin, G.; Huang, Z.; Yao, Y.; Liao, X.; Chen, A.; Pu, X.; Liao, L. Preparation, characterization and in vitro cytotoxicity of indomethacin-loaded PLLA/PLGA microparticles using supercritical $\mathrm{CO}_{2}$ technique. Eur. J. Pharm. Biopharm. 2008, 70, 85-97.

109. Yu, L.; Cai, D.; Wang, H.; Titirici, M.-M. Synthesis of microspherical $\mathrm{LiFePO}_{4}$-carbon composites for lithium-ion batteries. Nanomaterials 2013, 3, 443-452. 
110. How, C.W.; Rasedee, A.; Manickam, S.; Rosli, R. Tamoxifen-loaded nanostructured lipid carrier as a drug delivery system: Characterization, stability assessment and cytotoxicity. Colloids Surf. B Biointerfaces 2013, 112, 393-399.

111. Abdel-Mohsen, A.M.; Abdel-Rahman, R.M.; Fouda, M.M.G.; Vojtova, L.; Uhrova, L.; Hassan, A.F.; Al-Deyab, S.S.; El-Shamy, I.E.; Jancar, J. Preparation, characterization and cytotoxicity of schizophyllan/silver nanoparticle composite. Carbohydr. Polym. 2014, 102, 238-245.

112. Helfrich, A.; Bruchert, W.; Bettmer, J. Size characterization of Au nanoparticles by ICP-MS coupling techniques. J. Anal. At. Spectrom. 2006, 21, 431-434.

113. Yu, X.; Fan, H.; Liu, Y.; Shi, Z.; Jin, Z. Characterization of carbonized polydopamine nanoparticles suggests ordered supramolecular structure of polydopamine. Langmuir 2014, 30, 5497-5505.

114. Anuratha, M.; Jawahar, A.; Umadevi, M.; Sathe, V.G.; Vanelle, P.; Terme, T.; Meenakumari, V.; Benial, A.M.F. Orientation of $N$-(1-(2-chlorophenyl)-2-(2-nitrophenyl)ethyl)4-methylbenzenesulfonamide on silver nanoparticles: SERS studies. Spectrochim. Acta A Mol. Biomol. Spectrosc. 2014, 131C, 261-267.

115. Shi, J.; Hedberg, Y.; Lundin, M.; Wallinder, I.O.; Karlsson, H.L.; Möller, L. Hemolytic properties of synthetic nano- and porous silica particles: The effect of surface properties and the protection by the plasma corona. Acta Biomater. 2012, 8, 3478-3490.

116. Kuehl, C.; El-Gendy, N.; Berkland, C. NanoClusters surface area allows nanoparticle dissolution with microparticle properties. J. Pharm. Sci. 2014, 103, 1787-1798.

117. Nagaraja, A.T.; Pradhan, S.; McShane, M.J. Poly (vinylsulfonic acid) assisted synthesis of aqueous solution stable vaterite calcium carbonate nanoparticles. J. Colloid Interface Sci. 2014, 418, 366-372.

118. Rejman, J.; Oberle, V.; Zuhorn, I.S.; Hoekstra, D. Size-dependent internalization of particles via the pathways of chathrin- and caveolae-mediated endocytosis. Biochem. J. 2004, 377, 159-169.

119. Tavano, L.; Muzzalupo, R.; Mauro, L.; Pellegrino, M.; Andò, S.; Picci, N. Transferrin-conjugated pluronic niosomes as a new drug delivery system for anticancer therapy. Langmuir 2013, 29, 12638-12646.

120. Liu, D.; Chen, Y.; Feng, X.; Deng, M.; Xie, G.; Wang, J.; Zhang, L.; Liu, Q.; Yuan, P. Micellar nanoparticles loaded with gemcitabine and doxorubicin showed synergistic effect. Colloids Surf. B Biointerfaces, 2014, 113, 158-168.

121. Al Faraj, A.; Shaik, A.S.; Afzal, S.; Al Sayed, B.; Halwani, R. MR imaging and targeting of a specific alveolar macrophage subpopulation in LPS-induced COPD animal model using antibody-conjugated magnetic nanoparticles. Int. J. Nanomedicine 2014, 9, 1491-1503.

122. Min, Y.; Li, J.; Liu, F.; Padmanabhan, P.; Yeow, E.K.L.; Xing, B. Recent advance of biological molecular imaging based on lanthanide-doped upconversion-luminescent nanomaterials. Nanomaterials 2014, 4, 129-154.

123. Tavano, L.; Vivacqua, M.; Carito, V.; Muzzalupo, R.; Caroleo, M.C.; Nicoletta, F. Doxorubicin loaded magneto-niosomes for targeted drug delivery. Colloids Surf. B Biointerfaces 2013, 102, 803-807. 
124. Morán, M.C.; Nogueira, D.R.; Vinardell, M.P.; Miguel, M.G.; Lindman, B. Mixed protein-DNA gel particles for DNA delivery: Role of protein composition and preparation method on biocompatibility. Int. J. Pharm. 2013, 454, 192-203.

125. Wang, X.; Zhen, X.; Wang, J.; Zhang, J.; Wu, W.; Jiang, X. Doxorubicin delivery to 3D multicellular spheroids and tumors based on boronic acid-rich chitosan nanoparticles. Biomaterials 2013, 34, 4667-4679.

126. Lv, S.; Li, M.; Tang, Z.; Song, W.; Sun, H.; Liu, H.; Chen, X. Doxorubicin-loaded amphiphilic polypeptide-based nanoparticles as an efficient drug delivery system for cancer therapy. Acta Biomater. 2013, 9, 9330-9342.

127. Pollock, S.; Antrobus, R.; Newton, L.; Kampa, B.; Rossa, J.; Latham, S.; Nichita, N.B.; Dwek, R.A.; Zitzmann, N. Uptake and trafficking of liposomes to the endoplasmic reticulum. FASEB J. 2010, 24, 1866-1878.

128. Ng, C.-T.; Li, J.J.; Gurung, R.L.; Hande, M.P.; Ong, C.-N.; Bay, B.-H.; Yung, L.-Y.L. Toxicological profile of small airway epithelial cells exposed to gold nanoparticles. Exp. Biol. Med. 2013, 238, 1355-1361.

(C) 2014 by the authors; licensee MDPI, Basel, Switzerland. This article is an open access article distributed under the terms and conditions of the Creative Commons Attribution license (http://creativecommons.org/licenses/by/3.0/). 